\title{
Strain Rate Dependent Ductility and Strain Hardening in Q\&P Steels
}

\author{
CHRISTOPHER B. FINFROCK, MELISSA M. THRUN, DIPTAK BHATTACHARYA, \\ TREVOR J. BALLARD, AMY J. CLARKE, and KESTER D. CLARKE
}

\begin{abstract}
Due to their high strength, formability and affordable cost, quenched and partitioned (Q\&P) steels have shown the potential to reduce the mass of vehicles, thereby decreasing fuel consumption during service. Furthermore, because a lower mass of steel is used in each vehicle, energy consumption associated with the steelmaking process is also reduced. Q\&P steels utilize the deformation-induced martensitic transformation (DIMT) of metastable retained austenite to enhance ductility and strain hardening. Accordingly, improvement of mechanical performance is contingent on the ability to precisely control the chemical and mechanical stability of austenite. Considering the multitude of factors that influence austenite stability, optimizing microstructures to delay necking or fracture is challenging, particularly as temperature and strain rate increase. Tensile tests of an intercritically annealed C-Mn-Si Q\&P steel were performed over a range of strain rates $\left(10^{-4}\right.$ to $\left.10^{-1} \mathrm{~s}^{-1}\right)$ to evaluate effects on the DIMT and sheet tensile properties. As strain rates increased from $10^{-4}$ to $10^{-1} \mathrm{~s}^{-1}$, the uniform elongation decreased from approximately 19 to 14 pct. This reduction in uniform elongation is associated with a decrease in the strain hardening exponent near the onset of strain localization. Based on experimental data from this study and review of previous research, it is postulated that the strengthening contribution of DIMT is controlled by competing effects of: (i) a decreasing chemical driving force for DIMT caused by deformation-induced heat accumulation at higher strain rates and (ii) an increasing number of martensite nucleation sites. This suggests that tailoring austenite stability for specific deformation conditions could enable further optimization of formability and vehicle crash behavior.
\end{abstract}

https://doi.org/10.1007/s11661-020-06127-y

(c) The Minerals, Metals \& Materials Society and ASM International 2021

\section{INTRODUCTION}

AutomobiLE manufacturers are seeking pathways to reduce the mass of new vehicles using design optimization and structural materials selection. This is important because the implementation of lightweighting technologies reduces the amount of energy used and greenhouse gases emitted during manufacturing and driving of automobiles ${ }^{[1]}$ During manufacturing, reducing the mass of steel used in a vehicle can facilitate a proportional decrease in detrimental emissions generated by the steelmaking process (primarily from coke-making, blast furnace operation, and scrap reheating). ${ }^{[2]}$ In the use phase of the vehicle lifecycle, lightweighting can enhance driving efficiency by

CHRISTOPHER B. FINFROCK, MELISSA M. THRUN, DIPTAK BHATTACHARYA, TREVOR J. BALLARD, AMY J. CLARKE, and KESTER D. CLARKE are with the Colorado School of Mines, Advanced Steel Processing and Products Research Center, 1500 Illinois St., Golden, CO 80401. Contact e-mail: cfinfroc@mines.edu

Manuscript submitted 26 August 2020; accepted 7 December 2020.

Article published online January 19, 2021 decreasing engine, gradient, braking, and rolling resistance losses; consequently, the potential efficiency gains associated with lightweighting are significant for conventional petroleum, hybrid electric, and all electric vehicles. ${ }^{[1,3,4]}$ Considering a hypothetical mass reduction of $100 \mathrm{~kg}$ in a gasoline powered passenger car with a 200,000 km service life, Helms and Lambrecht reported a total energy savings of $23 \mathrm{GJ}$, leading to a savings of 700 liters of gasoline. ${ }^{[1]}$

For sheet steels, alloy design for lightweighting has enabled mass reductions in two ways. ${ }^{[2]}$ First, low-density steels containing high manganese and aluminum contents have been designed that reduce mass for a given thickness. Second, alloying and thermomechanical processing routes have been developed that create complex non-equilibrium microstructures with high strength and toughness. By enhancing the toughness and strength of a steel, the total sheet thickness can be reduced, with a corresponding decrease in vehicle mass.

In the context of emerging lightweighting strategies, automakers must maintain acceptable levels of passenger safety, sheet formability, and weldability. For instance, automobiles must retain the ability to absorb 
kinetic energy and prevent intrusion during a crash. By maximizing yield stress (YS) and ultimate tensile strength (UTS), crash performance can be preserved, despite a reduction in gauge thickness. ${ }^{[5]}$ Meanwhile, fracture strain and strain hardening must be tailored to delay failures in bending and stamping operations. To meet these goals, third generation advanced high strength steels (AHSS) offer improved toughness in comparison to first generation steels at a lower cost than second generation steels. ${ }^{[6]}$ Besides strength and formability, joinability of third generation AHSS is an additional consideration for crash worthiness and vehicle durability; resistance spot welding parameter selection, dissimilar material joining, and liquid metal embrittlement susceptibility are areas of active research. ${ }^{[7-10]}$

Quenched and partitioned (Q\&P) steels, conceptualized by Speer et al., ${ }^{[1-15]}$ were designed to meet the strength and ductility targets of AHSS with relatively low alloy contents. The quenching and partitioning process creates a martensitic-based microstructure containing a controlled volume fraction of metastable retained austenite. During sheet forming, some or all of the austenite in the Q\&P microstructure undergoes a deformation-induced martensitic transformation (DIMT). Additional DIMT may occur in the event of a vehicle crash, in cases when the austenite was not completely transformed to martensite during sheet forming and the crash-induced deformation conditions and austenite stability are suitable to facilitate additional transformation. The propensity for DIMT during a vehicle crash may also depend on the susceptibility of the austenite to transform or decompose while subjected to various temperatures during the automobile use phase (i.e., low temperatures during winter could induce the transformation to martensite while high summer temperatures could decompose austenite to ferrite and cementite). The DIMT causes the transformation-induced plasticity (TRIP) effect, ${ }^{[16,17]}$ wherein the volume expansion and distortions associated with the austenite to martensite transformation are accommodated through plastic straining of the austenite surrounding the newly formed martensite (Greenwood-Johnson effect $^{[18]}$ ) and through selection of preferred martensite variants (Magee effect ${ }^{[19]}$ ). The enhanced work hardening capacity due to DIMT is usually attributed to (a) increased dislocation density in the austenite and (b) increased content of hard freshly formed martensite, ${ }^{[20,21]}$ which induces a composite-like strengthening effect due to the plastic incompatibility of martensite with the surrounding softer matrix phases. Because the stability of retained austenite substantially influences mechanical performance, ${ }^{[6,20-23]}$ many studies intending to optimize alloying, heat treatment, and resulting microstructure have been performed for Q\&P steels. ${ }^{[2-29]}$ Deformation factors such as strain state, strain rate, strain path, and temperature also affect the apparent stability of austenite, which affect formability. ${ }^{[30-35]}$ For example, for a medium manganese TRIP steel, Wu et al. showed that strain path changes during forming can be manipulated to achieve a desired retained austenite content and mechanical properties in stamped parts. ${ }^{[36]}$

The deformation response of Q\&P steels under nonlinear and dynamic loading conditions is of paramount interest to the sheet forming community. This is because stamping operations and vehicle crashes generally impart deformation at high strain rates over complex pathways. ${ }^{[37]}$ Typical ranges of strain rates associated with sheet forming and vehicle crashes are approximately $10^{-1}$ to $10 \mathrm{~s}^{-1}$ and $10^{2}$ to $10^{3} \mathrm{~s}^{-1}$, respectively. ${ }^{[37-39]}$ At rates in excess of $10^{-2} \mathrm{~s}^{-1}$, deformation-induced heating is significant in the workpiece, ${ }^{[40-44]}$ which is problematic because the driving force for DIMT is intrinsically responsive to temperature. ${ }^{[45-51]}$ Furthermore, the number of shear band intersections increases significantly as strain rates are increased from quasi-static to dynamic; this is important because shear band intersections are considered to be the primary sites for martensite nucleation during DIMT.$^{[30,31,52-54]}$ To inform models that forecast critical material performance, such as surface strain distribution and the onset of necking, understanding DIMT in dynamic and nonisothermal conditions is essential. However, at strain rates greater than $1 \mathrm{~s}^{-1}$, mechanical testing becomes increasingly challenging due to load frame limitations and ringing artifacts. ${ }^{[38]}$ Accordingly, the test matrix investigated in this paper was selected to resolve a range of strain rates from $10^{-4} \mathrm{~s}^{-1}$, where deformation-induced heating is negligible, to $10^{-1} \mathrm{~s}^{-1}$, where heating is quasi-adiabatic. Additional testing at dynamic strain rates $\left(1\right.$ to $\left.10^{3} \mathrm{~s}^{-1}\right)$ is warranted to fully evaluate the strain hardening and DIMT response of AHSS during vehicle crashes; this testing is underway.

With the goal of improving formability and final part properties and performance, this paper discusses changes in TRIP behavior and mechanical response as deformation rates are increased from quasi-static $\left(10^{-4} \mathrm{~s}^{-1}\right)$ to intermediate $\left(10^{-1} \mathrm{~s}^{-1}\right)$. Experimental data are presented for an intercritically annealed Q\&P steel, where the microstructure contains intercritical ferrite with austenite and martensite typically found in Q\&P microstructures.

\section{MATERIALS AND METHODS}

A zinc-coated, $1.4 \mathrm{~mm}$-thick $0.2 \mathrm{C}-1.9 \mathrm{Mn}-1.6 \mathrm{Si}$ (wt pct) steel was intercritically annealed to form intercritical ferrite before Q\&P processing using commercial production equipment. The steel was designed to have an ultimate tensile strength of $980 \mathrm{MPa}$, leading to the designation QP980. A transverse section of the QP980 was metallographically mounted, ground, polished, and etched with 1 pct Nital solution. A JEOL 7000 field emission scanning electron microscope (SEM) in the secondary electron imaging mode was used to reveal intercritical ferrite, retained austenite, and martensite in the microstructure (Figure 1). The scale and morphology of the microstructure features appear consistent with previous characterization performed on QP980. In a previous study performed by the authors, which referred to the steel of interest as "QP980-B", 


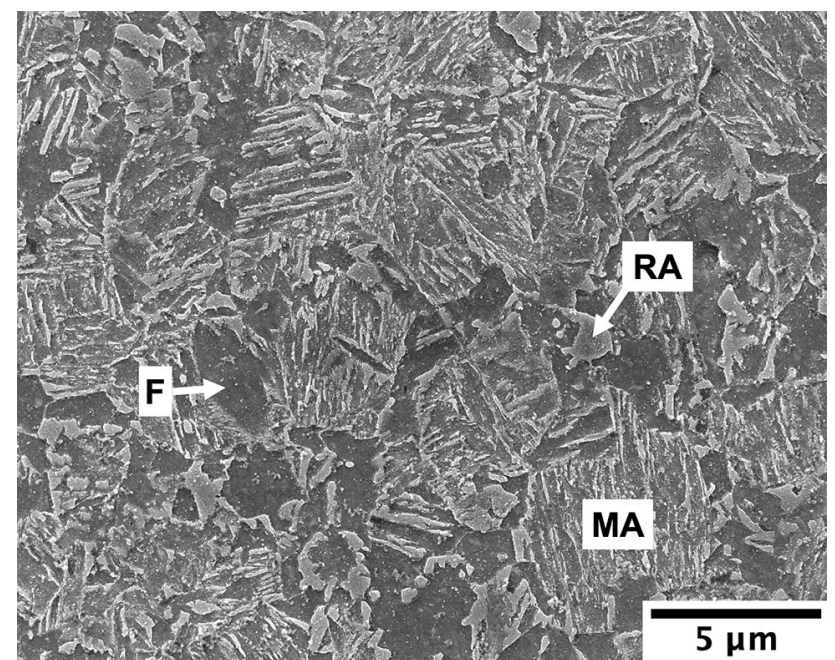

Fig. 1-SEM micrograph of a transverse cross-section of QP980. Retained austenite blocks (RA), intercritical ferrite (F) and martensite-austenite microconstituent (MA) are visible in the microstructure.

quantitative optical and electron microscopy and image analysis revealed the microstructure contained approximately 20 vol pct intercritical ferrite and 10 vol pct retained austenite, with the remainder being martensite. ${ }^{[22]}$ The retained austenite existed in both blocky and film type morphologies. The martensitic fraction of the microstructure was slightly tempered from the partitioning step of the Q\&P thermal cycle. DIMT was observed to occur most completely when QP980 was subjected to tensile strain along the rolling direction, rather than the transverse and diagonal directions. This was primarily attributed to crystallographic texture in the ferrite, martensite, and austenite inherited from thermomechanical processing..$^{[22,55]}$

Standard sheet-type tensile specimens conforming to ASTM E $8^{[56]}$ were removed from the rolling direction of the QP980 sheet. Interrupted and continuous tensile testing was performed using an MTS Alliance RT/100 load frame equipped with a two inch extensometer. Load-displacement data generated from each tensile test were normalized by the dimensions of each tensile specimen to compute true stress as a function of true strain, until the onset of strain localization. Ultimate tensile strength (UTS), 0.2 pct offset yield stress (YS), and uniform elongation (UE) were computed from engineering stress-strain data. Toughness was determined based upon the area under the engineering stress-strain curves from 0 pct strain until the onset of strain localization.

Variations in the strain hardening behavior of QP980 were assessed by several numerical methods. Instantaneous strain hardening exponent $\left(n_{i}\right)$ was calculated ${ }^{[57]}$ :

$$
n_{i}=\frac{d(\ln \sigma)}{d(\ln \varepsilon)}
$$

where $\sigma$ and $\varepsilon$ are true stress and true strain, respectively. In cases where $n_{i}$ was plotted against true strain, the running average of $n_{i}$ was computed with 50 adjacent values to smooth the curve. Average strain hardening exponent $(\bar{n})$ was computed as an average of $n_{i}$ over an interval of strain, i.e., $\bar{n}_{2.5-5 \text { pct }}$ is the average of $n_{i}$ from 2.5 to 5.0 pct true strain. To determine the various stages of strain hardening, the modified Crussard-Jaoul (C-J) analysis approach was used; in this method, ${ }^{[58]}$ changes in the slope of a $\ln (\mathrm{d} \sigma / \mathrm{d} \varepsilon)$ vs. $\ln \sigma$ plot can provide insights into the stages of strain hardening according to:

$$
\ln \left(\frac{d(\sigma)}{d(\varepsilon)}\right)=(1-m) \ln (\sigma)-\ln (C m)
$$

where $m$ is the C-J strain hardening exponent and $C$ is a material constant.

For selected strain rates, surface temperature evolution during deformation was measured by thermocouples and infrared thermography (IRT). K-type thermocouples were spot welded at three arbitrary locations on each gauge section to measure surface temperature during tensile elongation. For IRT, after specimens were painted with a thin layer of matte black paint to mitigate reflectivity of IR light in the laboratory, a FLIR A325sc thermal camera was used to record a heatmap video of the tensile tests.

During interrupted tests at a strain rate of $10^{-4} \mathrm{~s}^{-1}$, the tensile specimens were removed from the tensile frame at increments of approximately 2 pct true strain. During each interruption, X-ray diffraction (XRD) was used to measure the phase volume fraction of austenite and martensite/ferrite in the center of the gauge length of the tensile specimen. Two scans were performed prior to plastic deformation: the first was performed on an as-received specimen (zero applied tensile strain); the second was performed on a specimen that was subjected to elastic loading to $50 \mathrm{MPa}$ below the YS. For the monotonic testing, multiple samples were strained until failure at strain rates of $10^{-4}, 10^{-3}, 10^{-2}$, and $10^{-1} \mathrm{~s}^{-1}$. After fracture, XRD scans were performed in multiple locations on both the uniformly elongated gauge section and the grip section of two representative tensile specimens from each strain rate. Each XRD specimen was prepared by wet grinding, followed by polishing with diamond polishing compound to minimize the extent of grinding-induced deformation. As a result, XRD scans interrogated a region of the microstructure approximately $250 \mu \mathrm{m}$ beneath the zinc coating and $200 \mu \mathrm{m}$ beneath the steel surface. For interrupted and monotonic tests, XRD was performed using a PANalytical PW3040 and a PANalytical Empyrean, respectively. Both diffractometers were equipped with a copper X-ray source. After reflection-mode scans were performed over a $2 \theta$ range of 40 to $105 \mathrm{deg}$, the integrated intensities of austenite $\gamma(200), \gamma(220)$, $\gamma(311)$, and ferrite $\alpha(200), \alpha(211)$, and $\alpha(220)$ peaks were used to calculate the volume percent of austenite with the method outlined in ASTME975. ${ }^{[59,60]}$

\section{RESULTS}

\section{A. Interrupted Tensile Testing}

Interrupted tensile tests were performed at a quasistatic strain rate of $10^{-4} \mathrm{~s}^{-1}$ to measure the 
transformation of austenite to martensite during deformation. The true stress-strain curves of QP980 specimens loaded continuously and with interruptions for XRD analysis are plotted in Figure 2(a). First, the interrupted specimen was loaded to the nominal YS of QP980 (750 MPa); loading to the YS led to the appearance of a slightly more pronounced yield point in the interrupted specimen relative to the continuously loaded specimen. Subsequently, the interrupted specimen was strained in increments of approximately 2 pct, until strain localization.

The interrupted and continuously loaded specimens exhibited similar ductility. The interrupted specimen exhibited rounded yield points from 0 to 6 pct true strain. Rounded yield points have been reported for Q\&P steels during interrupted tests, ${ }^{[61]}$ and are morphologically consistent with the Haasen-Kelly effect. ${ }^{62,63]}$ After 6 pct true strain, serrated yield point phenomena occurred during reloading. The serrated yield points could be caused by static strain aging, or pinning of mobile dislocations by interstitial carbon atmospheres. ${ }^{[64]}$ Researchers have observed static strain aging in TRIP-assisted steels. ${ }^{[65-68]}$ Additionally, Portevin-Le Châtelier bands caused by dynamic strain aging have been observed at elevated temperatures (373 K to $523 \mathrm{~K}$ ) by Min et al. for a Q\&P steel with a similar microstructure to QP980. ${ }^{[69]}$ Despite these reports, the discovery of yield point reemergence during consecutive incremental strains at room temperature is novel in the literature for Q\&P steels. Because serrations consistent with strain aging appeared only after plastic tensile strains of several percent, it is theorized that static strain aging occurred in the strain-induced martensite. Strain-induced martensite likely has a solute carbon content sufficient to cause strain aging because: (a) the partitioning process increases the carbon content of the parent austenite above the bulk alloy composition and (b) the martensite has not been sufficiently tempered to form carbides. A recent study also revealed that that the average dislocation content in martensite formed by DIMT decreases with increasing strain amounts ${ }^{[70]}$; the reduced dislocation density in martensite might further explain the observed load drop or serrated yield point effect during interrupted tension tests.

To measure the extent of TRIP in the interrupted sample, retained austenite volume percent was measured using XRD at each strain increment. Shown in Figure 2(b), the transformation from austenite to martensite was exemplified by the reduction in retained austenite volume percent from approximately 10 to 5 pct at the end of uniform elongation. No DIMT was apparent during elastic loading; the volume fraction of retained austenite in the initial undeformed specimen was relatively similar to that in the elastically strained specimen. In contrast, measurable DIMT was detectable only after macroscopic yielding. Scatter in the retained austenite content of approximately one volume percent was evident, perhaps due to local variations in chemical composition and noise in the XRD scans. Despite the scatter, the presence of DIMT confirmed that the strain hardening of QP980 was enhanced by the TRIP-effect. Furthermore, the DIMT response reported here was comparable to similar Q\&P steels analyzed using synchrotron radiation by AbuFahra et al. ${ }^{[71]}$ and $\mathrm{Hu}$ et al. ${ }^{[72]}$ In the same synchrotron-based investigation of a Medium-Mn steel, Abu-Fahra et al. observed that propagative instabilities (Portevin-Le Châtelier bands) led to inhomogeneous DIMT due to the nonuniform strain in the vicinity of the deformation bands. ${ }^{[71]}$ For the present interrupted testing of QP980, the occurrence of serrated yielding suggests the brief progression of inhomogeneous

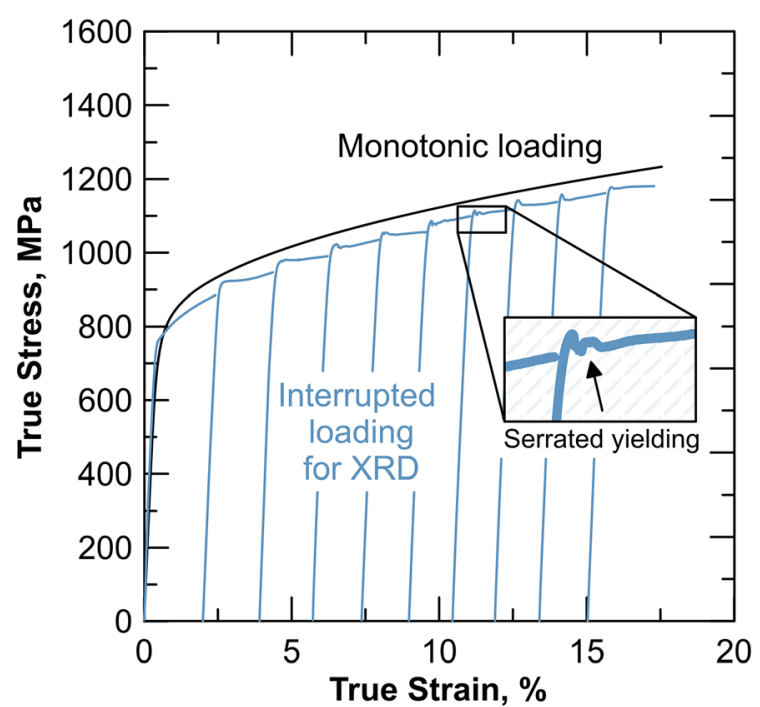

(a)

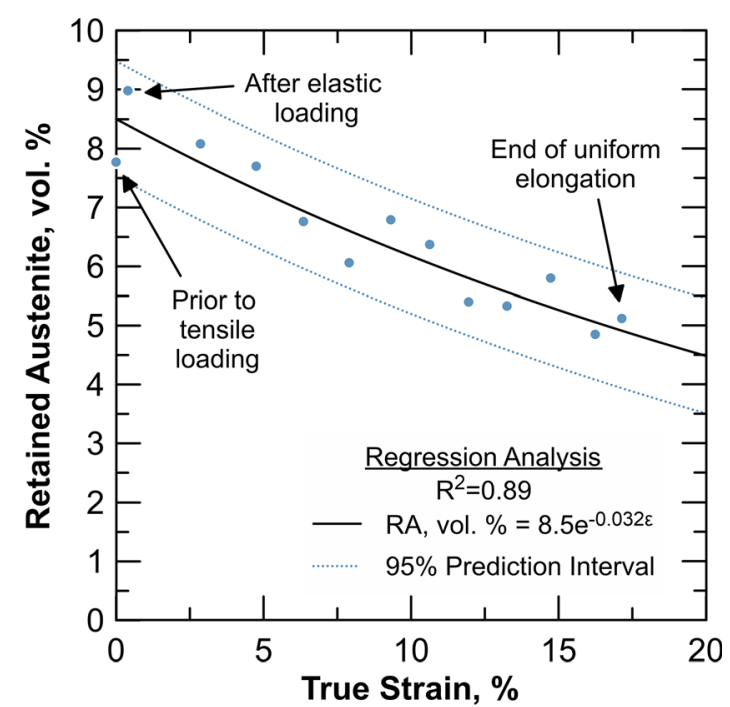

(b)

Fig. 2-(a) True stress-strain curves for monotonic and interrupted tensile tests of QP980. During each interruption, the QP980 specimen was removed from the tensile frame for measurement of retained austenite content with XRD. (b) Retained austenite content (in volume percent) as a function of true strain, measured in interrupted tensile specimens. The retained austenite content diminished during tensile deformation. Regression analysis was performed to quantify the variability in XRD data (standard error $=0.42$ vol pct). 
deformation. Thus, based on the analysis by Abu-Fahra et al., ${ }^{[71]}$ it is imperative to note that the authors of this study cannot rule out the possibility that DIMT progressed nonuniformly during serrated yielding. Further work is warranted to elucidate the effects of strain interruptions and strain aging on the extent and character of DIMT.

\section{B. Deformation Response at Various Strain Rates}

Figure 3 presents true stress-strain curves of QP980 specimens continuously strained to failure at rates of $10^{-4}, 10^{-3}, 10^{-2}$, and $10^{-1} \mathrm{~s}^{-1}$. Despite nearly identical roundhouse yielding behavior for specimens deformed at all strain rates, the specimens appeared to exhibit strain-rate dependent ductility; as strain rates were increased from $10^{-4}$ to $10^{-1} \mathrm{~s}^{-1}$, the uniform elongation repeatably decreased from approximately 19 to 14 pct.

As a consequence of the instability criterion for uniaxial tensile tests, the onset of strain localization occurs when $n_{i}$ is equal to the true strain. ${ }^{[73]}$ Accordingly, $n_{i}$ was computed from stress-strain data to assess how the strain rate dependent work hardening rate of QP980 resulted in changes in uniform elongation. In Figure $4, n_{i}$ is plotted as a function of true strain for each specimen. For all strain rates, $n_{i}$ reached a minimum at approximately 2 pct true strain, then increased with additional strain. In the $10^{-4} \mathrm{~s}^{-1}$ specimens, $n_{i}$ continued to climb until failure. For the $10^{-3} \mathrm{~s}^{-1}$ specimens, the shape of the curve was similar, although $n_{i}$ was lower. Meanwhile, for the two higher strain rate tests $\left(10^{-2}\right.$ and $\left.10^{-1} \mathrm{~s}^{-1}\right), n_{i}$ began to decrease at true strains above approximately 8 pct. It is notable that curves for $10^{-2}$ and $10^{-1} \mathrm{~s}^{-1}$ appeared nearly identical. Because the higher strain rate specimens exhibited comparatively low strain hardening rates after approximately 8 pct true strain, those specimens formed necks at the lowest true strains, in agreement with the tensile instability criterion.

Fundamental tensile properties, determined from the stress-strain behavior, are plotted as a function of strain rate in Figure 5. No clear trend is apparent between either UTS or YS and strain rate (Figure 5(a)); neither UTS nor YS appear to be strain rate sensitive in the tested strain rate regime. In Figure 5(b), $\bar{n}$ is plotted for increments of true strain from 2.5 pct until failure. For true strains from 2.5 to 10 pct, i.e., for $\bar{n}_{2.5-5 \mathrm{pct}}, \bar{n}_{5-7.5 \mathrm{pct}}$, and $\bar{n}_{7.5-10 \mathrm{pct}}$, the average strain hardening rate was marginally responsive to strain rate. However, at true strains above $10 \mathrm{pct}$, i.e., for $\bar{n}_{10} \mathrm{pct}$ to failure, the average strain hardening rate greatly diminished as the strain rate increased from $10^{-4}$ to $10^{-1} \mathrm{~s}^{-1}$. The responses of UE and toughness to strain rate are denoted in Figures 5(c) and (d), respectively. Toughness was computed based on the area under the engineering stressstrain curve from the beginning of loading until the onset of necking. On average, increasing the strain rate from $10^{-4}$ to $10^{-1} \mathrm{~s}^{-1}$ decreased UE by 29.9 relative percent and toughness by 31.2 relative percent. UE and toughness decreased by similar extents, because the flow stress of QP980 was not strongly strain rate sensitive at any given strain value.

As shown in Figures 4 and 5, the instantaneous strain hardening exponent changed as a function of both true strain and strain rate. To assess the stages of strain hardening at the lowest and highest rates, i.e., $10^{-4}$ and $10^{-1} \mathrm{~s}^{-1}$, a modified C-J analysis was performed. ${ }^{[58]}$ The linear regions of the $\ln (\mathrm{d} \sigma / \mathrm{d} \varepsilon)$ v s. $\ln (\sigma)$ curves in Figure 6 show that deformation at both strain rates induced multi-stage strain hardening behavior. While stages I, II, and III were present for both strain rates, stage IV was observed in the high-rate specimen only. Soares et al. and Skowronek et al. have provided speculation about origins of each strain hardening stage $^{[74,75]}$; stages I, II, and III are perhaps associated

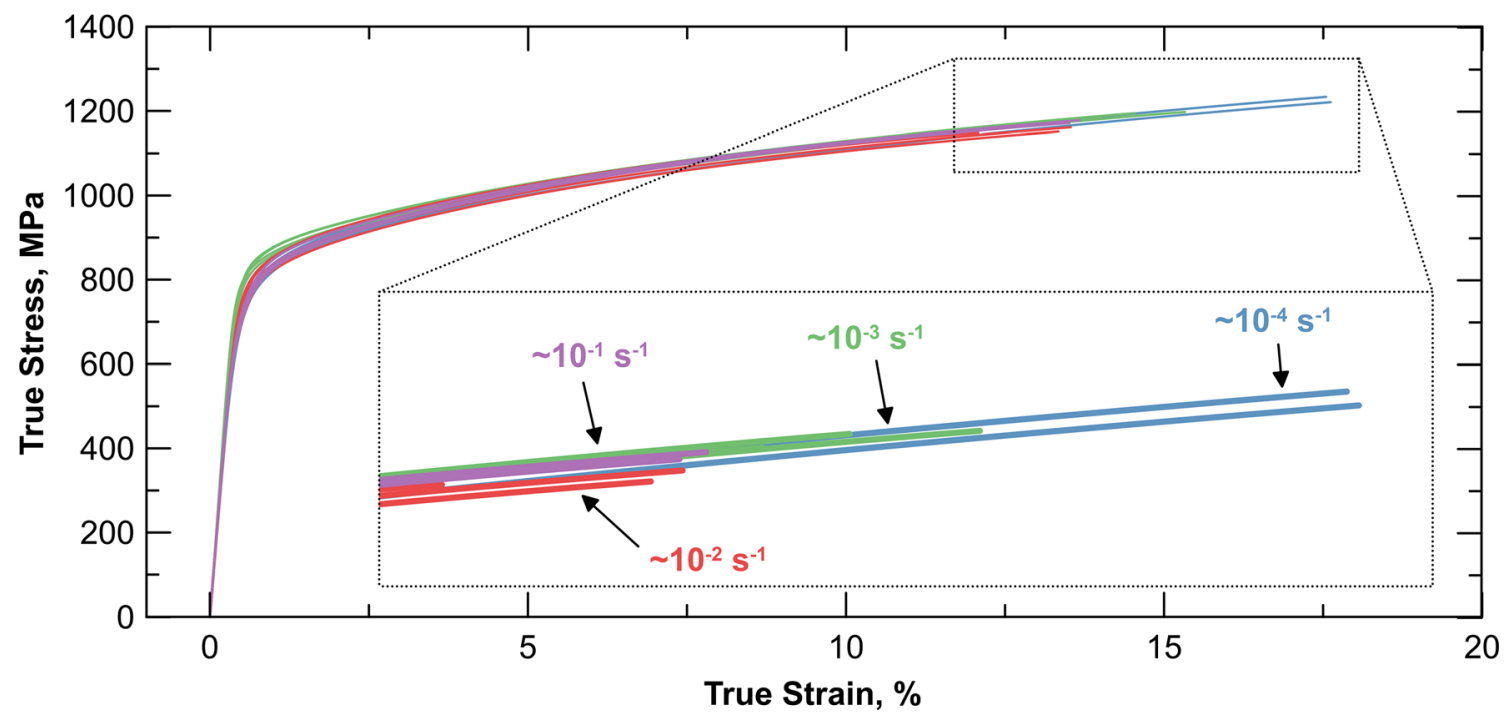

Fig. 3-True stress-strain response of QP980 deformed at approximate strain rates of $10^{-4} \mathrm{~s}^{-1}$ (blue), $10^{-3} \mathrm{~s}^{-1}$ (green), $10^{-2} \mathrm{~s}^{-1}$ (red) and $10^{-1}$ $\mathrm{s}^{-1}$ (purple). Despite the comparable roundhouse yielding behavior of each specimen, increasing strain rate significantly decreased the amount of uniform elongation (Color figure online). 


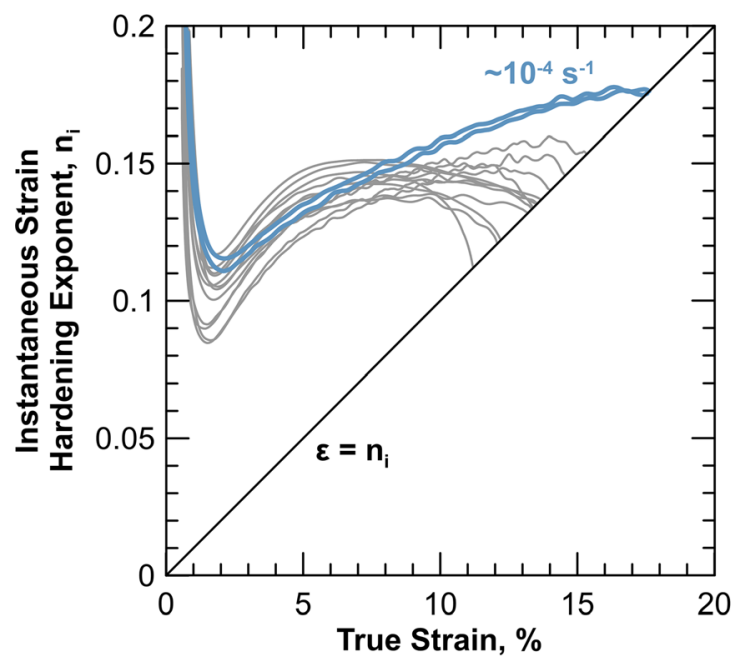

(a)

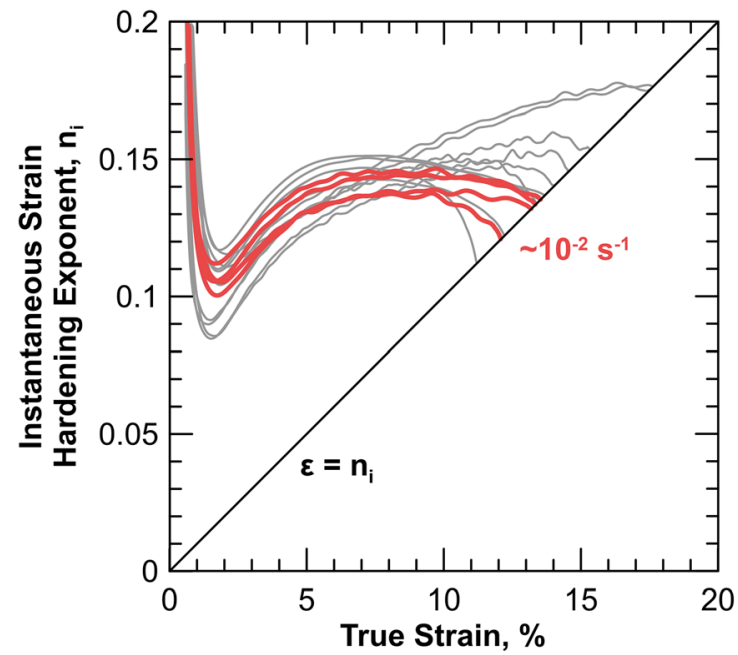

(c)

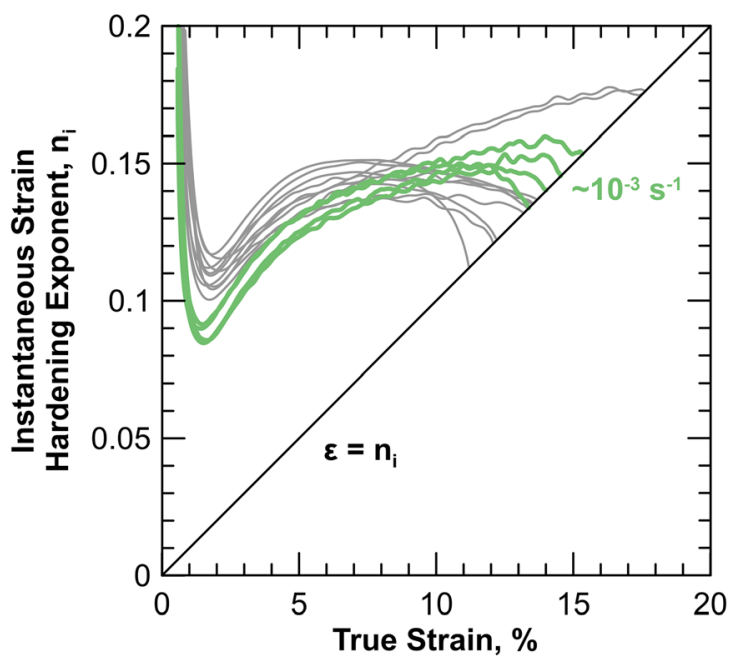

(b)

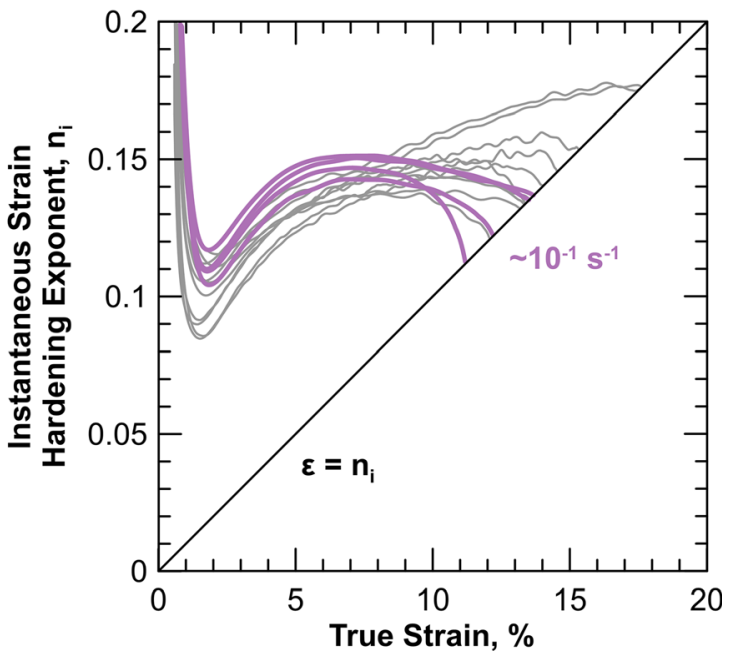

(d)

Fig. 4-Instantaneous strain hardening exponent, $n_{i}$, plotted as a function of true strain for every tensile specimen. Curves from every strain rate are plotted separately in $(a$ through $d$ ) to enable comparison; curves from the labeled strain rate are plotted in color while curves from other strain rates are plotted in gray. For reference, the tensile instability criterion $\left(\varepsilon=\mathrm{n}_{\mathrm{i}}\right)$ is also plotted.

with the onset of plastic deformation near the yield stress, slip of mobile dislocations in intercritical ferrite, and strain accommodation by the TRIP-effect, respectively. Stage IV is associated with the exhaustion of the TRIP-effect and slip in the ferrite/bainite, martensite, and remaining retained austenite. The presence of stage IV hardening in the high-rate specimens suggests that DIMT was suppressed in the final stages of uniform straining, facilitating the rapid decrease in the instantaneous strain hardening exponent shown in Figure 4(d). Interrupted or in-situ testing aimed to resolve local strain partitioning and austenite phase volume fraction (see Salehiyan et al. ${ }^{[76]}$ ) would be useful to confirm if DIMT was suppressed during stage IV hardening.

\section{Deformation-Induced Heating}

Surface temperature was measured during tensile deformation for selected specimens to elucidate the contribution of deformation-induced heating to the strain hardening response of QP980. During the quasi-static tests $\left(10^{-4} \mathrm{~s}^{-1}\right)$, the surface temperature remained within several degrees Celsius of room temperature. Although heat was necessarily generated by the mechanical work imparted during plastic deformation, the heat was allowed to dissipate into the air and grip fixtures during the approximately forty-minute tensile tests. Meanwhile, at strain rates of $10^{-3} \mathrm{~s}^{-1}$, Poling and Connolly et al. have shown that deformation-induced heating leads to temperature rises of 


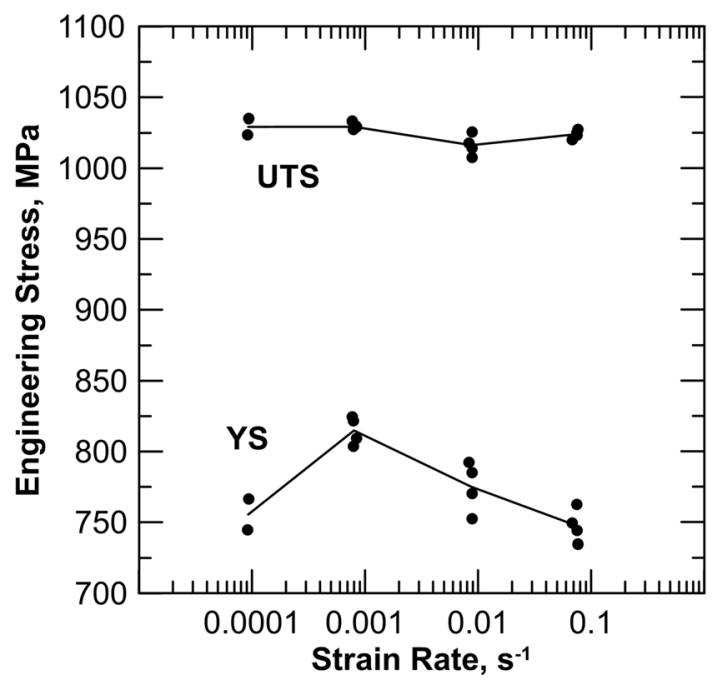

(a)

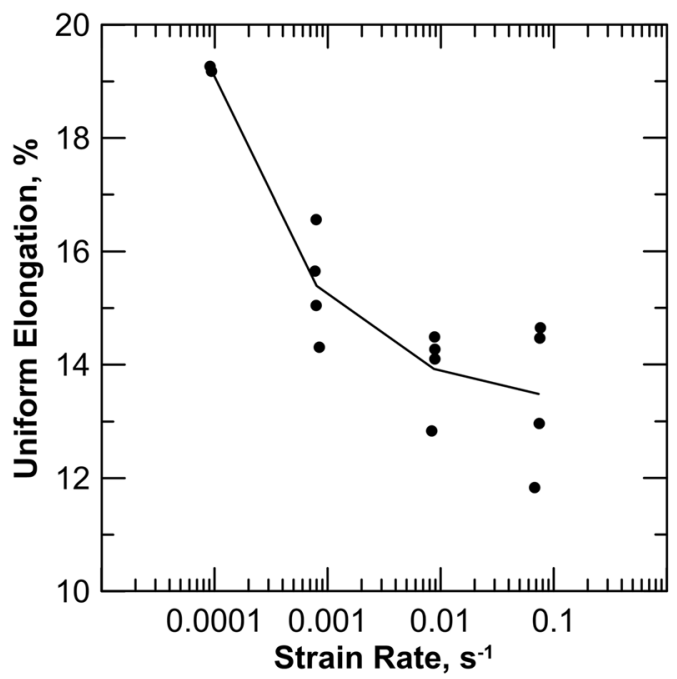

(c)

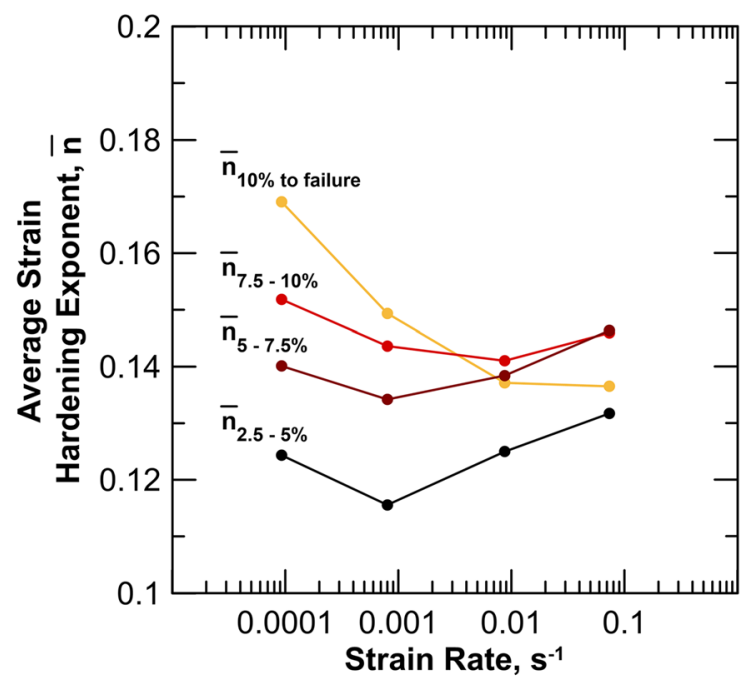

(b)

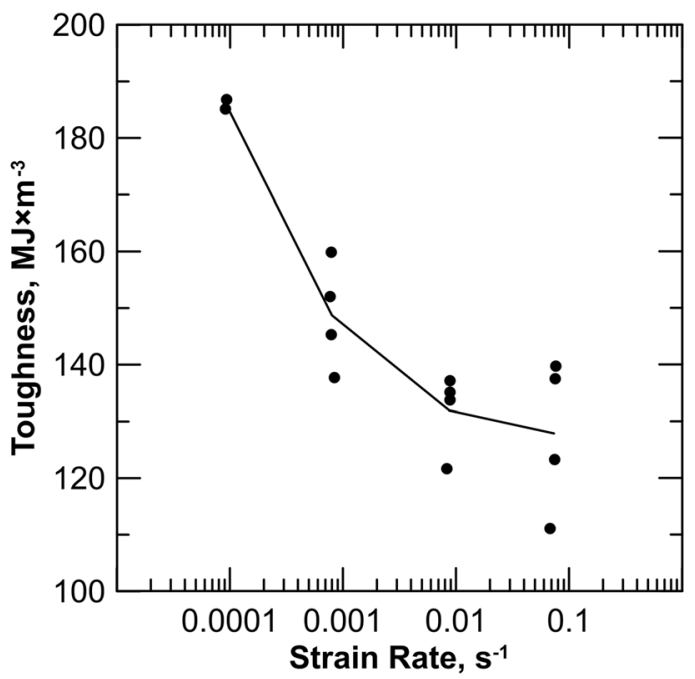

(d)

Fig. 5- (a) UTS and YS, $(b) \bar{n},(c)$ UE, and (d) toughness plotted as a function of engineering strain rate. $\bar{n}$, UE, and toughness appear to be strain rate sensitive. The average strain hardening exponent at high strains $\left(\bar{n}_{10}\right.$ pctfailure $)$ decreased at higher strain rates, facilitating a decrease in uniform elongation, in accordance with the tensile instability criterion.

approximately $15^{\circ} \mathrm{C}^{[40,77]}$; at this strain rate, only some of the deformation-induced heat was allowed to dissipate into the environment (i.e., the deformation was neither isothermal nor adiabatic). In this study, for the higher strain rate tests $\left(10^{-2}\right.$ and $\left.10^{-1} \mathrm{~s}^{-1}\right)$, the tensile tests occurred over an average duration of 20 and 2 seconds, respectively. At such high rates of deformation, the surface temperature of the tensile specimens rose from room temperature to approximately $55^{\circ} \mathrm{C}$ at the onset of localization. Surface temperature evolution for specimens deformed at of $10^{-2}$ and $10^{-1} \mathrm{~s}^{-1}$ is plotted as a function of true strain in Figure 7(a), which clearly indicates deformation-induced heating of specimens strained at high rates.

A simple model was applied to predict the temperature rise of a specimen deformed at a rate of $10^{-1} \mathrm{~s}^{-1}$, assuming no dissipation of deformation-induced heat (i.e., adiabatic conditions). For the purpose of the model, it was assumed that 90 pct of the mechanical work imparted on the tensile specimen was available to evenly heat the specimen; expressed as a decimal, this term is known as the Taylor-Quinney coefficient. ${ }^{[78]}$ The predicted temperature reached was computed ${ }^{[79]}$ :

$$
T_{\text {adiabatic }}=T_{r t}+\frac{0.9 \int_{0}^{\varepsilon} \sigma d \varepsilon}{\rho C}
$$

where $T_{r t}=21.4^{\circ} \mathrm{C}, C=495 \frac{\mathrm{J}}{\mathrm{kg}^{\circ} \mathrm{C}}, \rho=7860 \frac{\mathrm{kg}}{\mathrm{m}^{3}},{ }^{[80]}$ and $\int_{0}^{\varepsilon} \sigma d \varepsilon$ was computed empirically from the area under a representative tensile curve $\left(10^{-1} \mathrm{~s}^{-1}\right)$ up to a given tensile strain and has units of $\frac{\mathrm{J}}{\mathrm{m}^{3}}$. Note that temperature increases associated with the exothermic martensitic transformation are not incorporated into the model, but have been observed by Vázquez-Fernández et al. for 
austenitic stainless steels. ${ }^{[81]}$ Vázquez-Fernández et al. reported that the extent of heat generation associated with the martensitic transformation can be incorporated into the model by changes in the Taylor-Quinney coefficient. For example, the Taylor-Quinney coefficient of a fully stable austenitic steel (AISI 316) was lower than a metastable austenitic steel (AISI 301), the latter

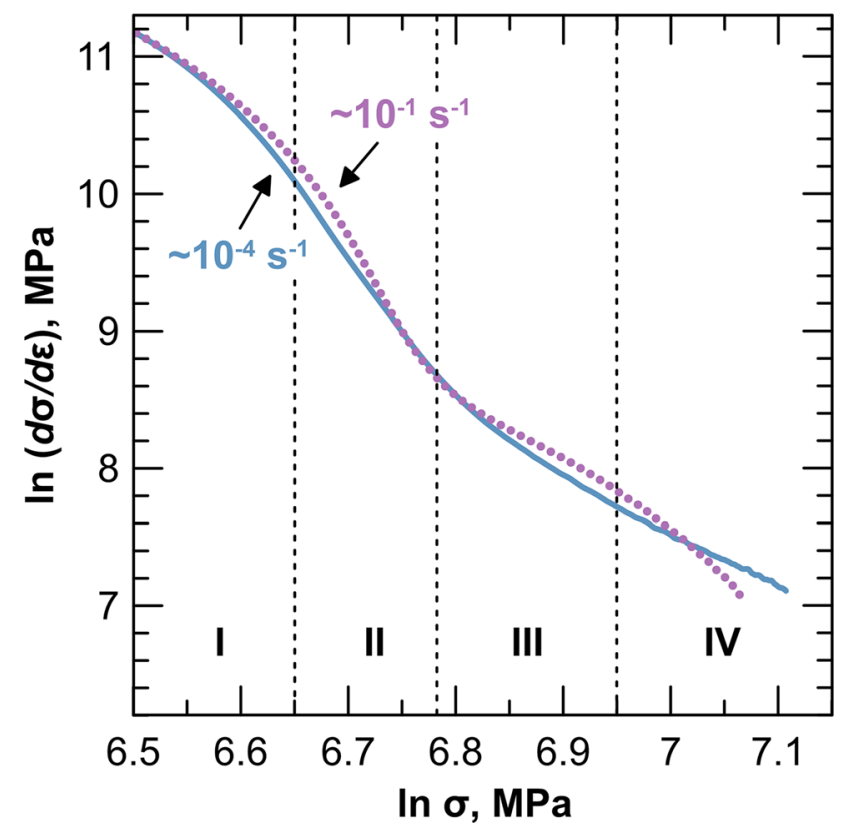

Fig. $6-\ln (\mathrm{d} \sigma / \mathrm{d} \varepsilon)$ vs. $\ln \sigma$ curves for the modified C-J analysis of representative specimens deformed at approximate strain rates of $10^{-4} \mathrm{~s}^{-1}$ (blue solid line) and $10^{-1} \mathrm{~s}^{-1}$ (purple dotted line). Four apparent stages of strain hardening are labelled (I, II, III, and IV) (Color figure online). of which presumably exhibited more DIMT during uniaxial tension testing and thus more deformation-induced heating. ${ }^{[81]}$ Based on these findings, the study proved the necessity of simultaneous measurement of surface temperature and strain for validating deformation-induced heating models of steels containing metastable austenite. This experimental approach, coupled with in-situ measurement of austenite volume fraction, would be highly useful for resolving DIMT and forming response under nonlinear strain paths, strain states including but not limited to uniaxial tension, and strain rates relevant to stamping $\left(10^{-1}\right.$ to $\left.10 \mathrm{~s}^{-1}\right)$ and vehicle crashes $\left(10^{2}\right.$ to $\left.10^{3} \mathrm{~s}^{-1}\right)$. For instance, such an approach could quantify the potential surface temperature inhomogeneity arising from the nonuniform deformation and DIMT reported by Abu-Fahra et al. ${ }^{[71]}$ Furthermore, this approach would be useful for developing and validating damage-based models that incorporate the strain state, strain path, strain rate, stress triaxiality, Lode angle, and temperature dependence of DIMT for determining the damage locus (for example, see Kim et al. ${ }^{[82]}$ ).

Temperature response projected by the adiabatic heating model is plotted alongside the actual thermocouple data in Figure 7(a). The model forecasted heating behavior that was nearly identical to the actual heating behavior for specimens deformed at the strain rates of $10^{-2}$ and $10^{-1} \mathrm{~s}^{-1}$; this equivalence suggests that both strain rates produced ostensibly adiabatic conditions. This finding was consistent with work by Clarke et al., who analyzed deformation-induced temperature rises both theoretically and experimentally over a range of strain rates and thicknesses for ferritic stainless steels. ${ }^{[4]}$ Clarke et al. determined that adiabatic conditions were reached more rapidly as specimen

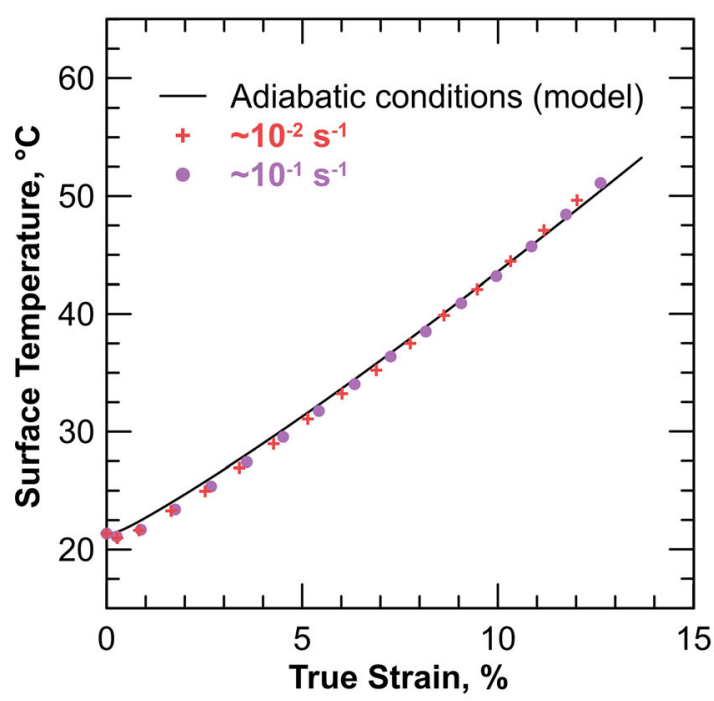

(a)
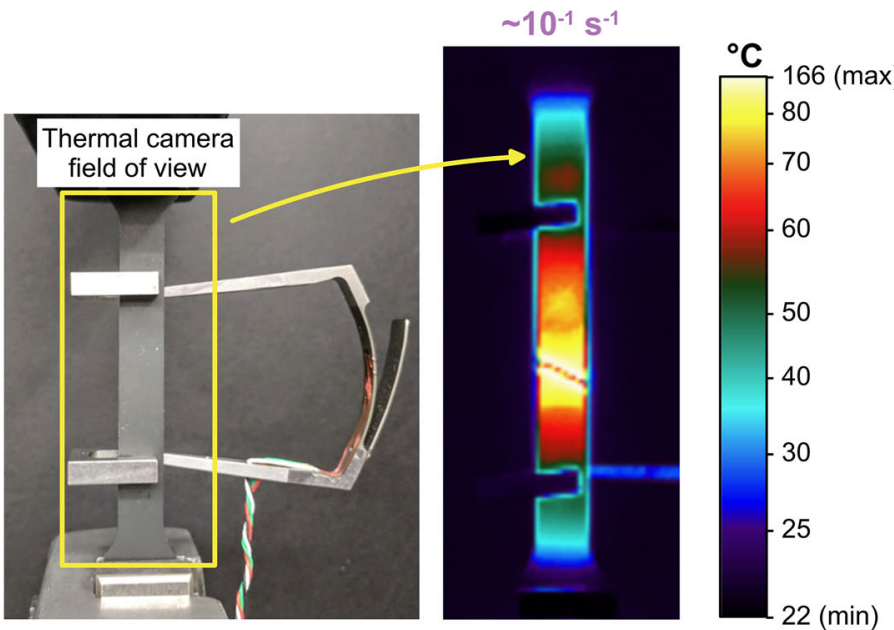

(b)

Fig. 7-(a) Calculated and measured deformation-induced heat accumulation in tensile specimens deformed at high strain rates. Surface temperature measurements were recorded with thermocouples during uniform elongation for specimens deformed at $10^{-2}$ and $10^{-1} \mathrm{~s}^{-1}$. Each specimen heated in a manner nearly identical to the empirically developed adiabatic heating model. (b) IRT heatmap revealing a rise in the surface temperature to approximately $160{ }^{\circ} \mathrm{C}$ in the neck (the diagonal region in the center of the specimen) of a tensile specimen deformed at an engineering strain rate of $10^{-1} \mathrm{~s}^{-1}$. 
thickness increased; based on these findings, the onset of quasi-adiabatic conditions at a strain rate of $10^{-2} \mathrm{~s}^{-1}$ is realistic for the $1.4 \mathrm{~mm}$-thick QP980 investigated in this study. This suggests that for strain rates higher than $10^{-2} \mathrm{~s}^{-1}$, the temperature rise would not drastically change without a proportional shift in the stress-strain curve or DIMT.

In a previous paper, ${ }^{[42]}$ it was concluded that thermocouples were unreliable for measuring temperature evolution during post-uniform elongation, and IRT provided a robust method to measure the uneven heating that occurred after the onset of strain localization. Accordingly, IRT was used here to evaluate temperature rise in the region of the neck; a map of the surface temperature distribution for a specimen deformed to failure at a strain rate of $10^{-1} \mathrm{~s}^{-1}$ is shown in Figure 7(b). Although the specimen reached a temperature of approximately $55^{\circ} \mathrm{C}$ at the onset of localization, the neck subsequently reached a temperature of approximately $160{ }^{\circ} \mathrm{C}$ at fracture. The sharp rise in temperature was seemingly reasonable, because the region of the neck was subjected to drastically higher strain rates, effective strains, and true stresses than the rest of the tensile specimen. A thermal gradient adjacent to the two extensometer attachment pins was visible in the IRT data; this suggests that environmental conditions, such as geometry of the sheet-tool interface, may influence heat dissipation in deformation processing operations.

\section{Deformation-induced Transformation of Austenite to Martensite}

XRD scans were performed to consider whether the reduction in strain hardening exponent at elevated strain rates could be attributed to a less predominant
TRIP-effect. For a representative tensile specimen deformed at $10^{-3} \mathrm{~s}^{-1}$, Figure 8(a) depicts example scan locations and XRD spectra used to calculate retained austenite volume percent in the grip section (nominally zero strain) and the uniformly elongated gauge section. Note that although only one scan is depicted in each region on the schematic, two scans were performed in each region to account for possible local variations in austenite content. For each QP980 specimen strained at different rates, the integrated intensities of austenite peaks were diminished in comparison to ferrite/martensite peaks, suggesting that austenite transformed to martensite during deformation at all strain rates. The relative amounts of DIMT as a function of the applied strain rate are shown in Figure $8(\mathrm{~b})$. The greatest transformation of retained austenite occurred at the slowest strain rate, suggesting that a greater volume fraction of retained austenite was available to facilitate TRIP. Generally, higher strain rate specimens exhibited less DIMT. However, variability in local austenite content prior to deformation caused some variability between replicates (see error bars). Meanwhile, replicate scans of the same region of the specimen exhibited nearly identical austenite contents, suggesting that noise error from the XRD measurement technique was minimal.

\section{E. Fractographic Analysis}

The true stress-strain response of QP980 presented in Figure 3 exemplified deformation behavior consistent with AHSS of similar alloy content and processing. Furthermore, specimens deformed at every strain rate exhibited significant post-uniform elongation (several percent engineering strain) prior to fracture. Despite the exhibition of these principally ductile behaviors for all

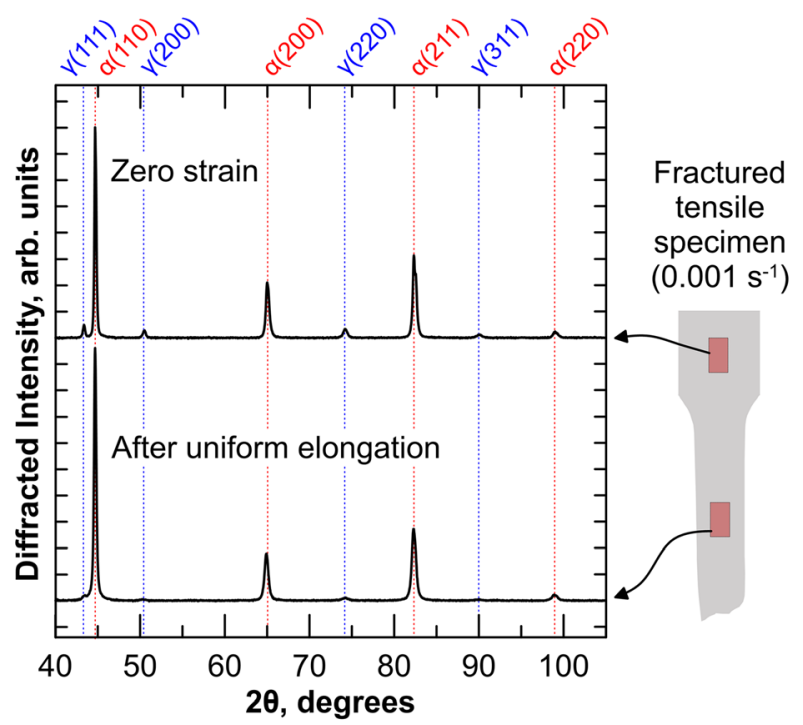

(a)

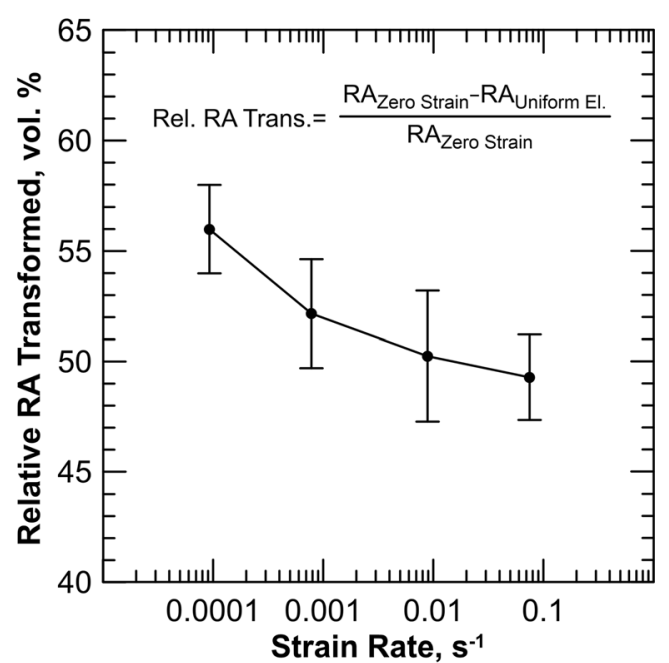

(b)

Fig. 8- (a) Representative XRD scans of QP980 before deformation (zero strain) and after uniform elongation at a strain rate of $10^{-3} \mathrm{~s}^{-1}$. (b) Relative amount of retained austenite transformed during uniform elongation plotted as a function of strain rate. Error bars are the standard deviation from four XRD scans performed in the gauge sections of two representative tensile specimens deformed at each strain rate. 


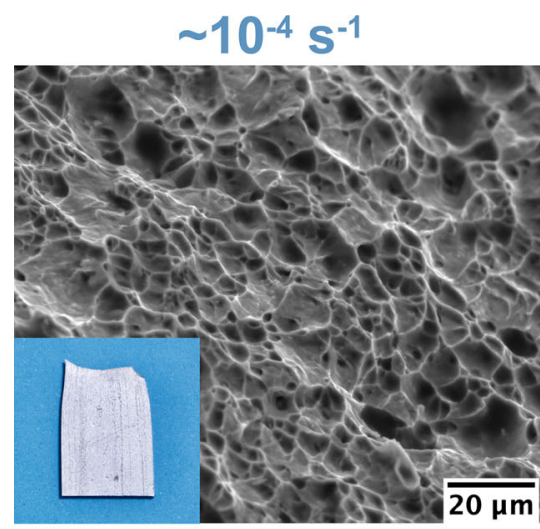

(a)

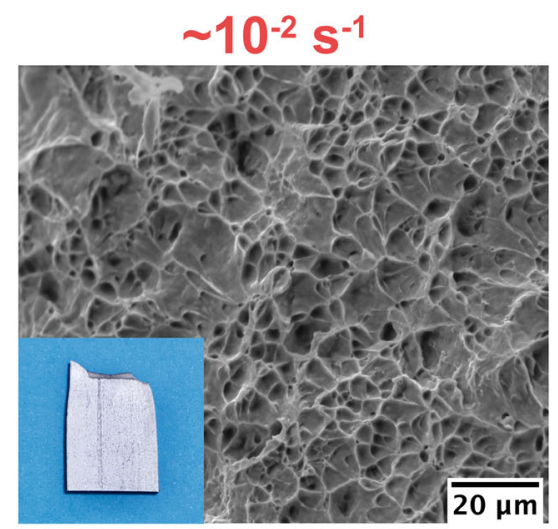

(b)

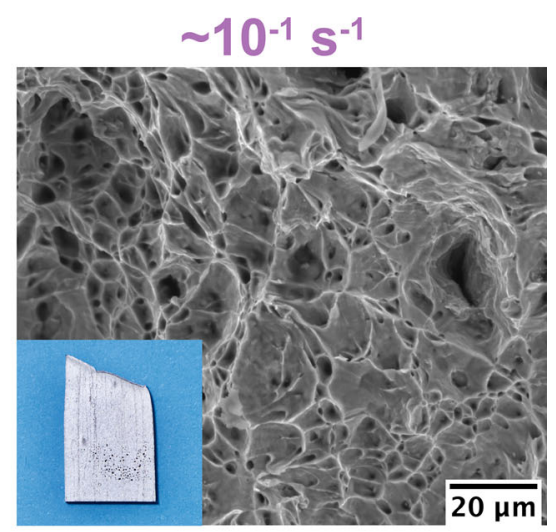

(c)

Fig. 9-Fractographs of QP980 deformed at rates of approximately (a) $10^{-4} \mathrm{~s}^{-1}$, (b) $10^{-2} \mathrm{~s}^{-1}$ and (c) $10^{-1} \mathrm{~s}^{-1}$. Viewed optically, specimens deformed at each strain rate exhibited macroscopically ductile diffuse and localized necking behavior. For scale of the inset images, the initial gauge width of each tensile specimen was $12.7 \mathrm{~mm}$. Viewed at higher magnification with SEM, ductile microvoids were evident on the fracture surface of each specimen.

strain rates, specimens deformed at higher strain rates generally exhibited reduced UE and toughness. In an attempt to identify the root-cause of the reduction in toughness, OM and SEM fractography was performed. Figure 9 shows representative OM and SEM images of the necks and fracture surfaces, respectively. At every strain rate, diffuse necking occurred prior to the formation of a localized neck. The shape and size of each diffuse neck appeared similar, with no evidence of a strain rate dependent shift in morphology. Viewed with SEM, the entirety of each fracture surface was decorated with ductile microvoids, suggesting that microvoid coalescence and growth preceded fracture during deformation at each strain rate. Watershed image analysis in previous work showed that dimple size and morphology did not change significantly between each strain rate, ${ }^{42]}$ suggesting that a shift in microvoid accumulation in the microstructure was not a valid explanation for the reduction in toughness. After ruling out microvoid accumulation, a shift in the TRIP-effect is perhaps the most rational cause of the strain rate dependent ductility.

\section{DISCUSSION}

\section{A. Strain Rate Sensitive TRIP-Effect in QP980}

Deformation-induced heat accumulation in tensile samples deformed at $10^{-2}$ and $10^{-1} \mathrm{~s}^{-1}$ led to a rise in surface temperature to approximately 53 and $160{ }^{\circ} \mathrm{C}$ at UTS and final fracture in the neck, respectively. Meanwhile, for samples deformed at $10^{-4} \mathrm{~s}^{-1}$, the surface temperature did not increase measurably. In a previous study of QP980, ${ }^{[42]}$ it was hypothesized that for elevated strain rate conditions, deformation-induced heat accumulation would increase the stability of the retained austenite, reduce the work hardening rate, and facilitate early necking. The DIMT and strain hardening data presented here support this hypothesis; as the samples heated quasi-adiabatically, the TRIP mechanism became less active and the average strain hardening rate near failure $\left(\bar{n}_{10} \mathrm{pct}\right.$ to failure $)$ was reduced. However, at small strains $\left(\bar{n}_{2.5-5 \mathrm{pct}}\right.$ and $\left.\bar{n}_{5-7.5 \mathrm{pct}}\right)$ before deformation-induced heating significantly increased specimen temperature, the average strain hardening rate appeared to be relatively constant. This suggests that examining the entire instantaneous strain hardening exponent curve is necessary for assessing the mechanisms that dictate the extent of DIMT. Based on the data presented here, it is apparent that strain rate sensitivity of the TRIP-effect may facilitate substantial shifts in the work hardening behavior and consequently the toughness.

\section{B. Mechanical Performance and DIMT in TRIP-Assisted AHSS}

To contextualize the behavior of QP980, a literature review pertaining to the role of temperature and strain rate on TRIP and mechanical performance is justified. Generally, elevated specimen temperature increases strain rate sensitivity and decreases the work hardening rate and flow stress. ${ }^{[37,57]}$ Additionally, several mechanisms for temperature dependence of TRIP have been discussed in this paper. First, the chemical driving force $\left(\Delta \mathrm{G}^{\gamma \rightarrow \alpha^{\prime}}\right)$ for austenite to martensite transformation decreases as specimen temperature rises. ${ }^{[45-50]}$ Second, stacking fault energy is temperature dependent, which can control the number of shear band intersections (the primary nucleation sites of martensite) that form during deformation. ${ }^{[30,31,52-54]}$ Hecker et al. demonstrated the contribution of both mechanisms in austenitic stainless steel, by showing that the number of shear band intersections increased at higher strain rates, but the lowered chemical driving force for martensitic transformation reduced the transformation rate as deformation-induced heat accumulated in the specimens. ${ }^{[30,31]}$ Similarly, for a Q\&P steel deformed isothermally at a quasi-static rate, Coryell et al. showed that DIMT reached a minimum at temperatures of approximately $150{ }^{\circ} \mathrm{C}$, leading to a 30 pct reduction in tensile 
elongation. ${ }^{[83]}$ The minimization of the TRIP-effect led to more predominant slip. The study also noted that austenite stability could be influenced by additional mechanisms during prolonged exposure to elevated temperatures, including additional carbon partitioning and bake hardening.

As was shown in this study and by others, ${ }^{440,44,77,84]}$ for quasi-static to intermediate strain rates, increasing the strain rate increases the temperature reached during deformation. This is because the deformation-induced heat is given less time to dissipate during shorter duration mechanical tests. ${ }^{[4]}$ However, there is a critical strain rate beyond which heating is quasi-adiabatic; in such conditions, virtually no heat dissipates into the environment. Zou et al. concluded that the adiabatic critical strain rate was reached for one $1.2 \mathrm{~mm}$-thick Q\&P steel around $10^{-1} \mathrm{~s}^{-1}$; this threshold strain rate was incorporated into a DIMT model with reasonable agreement with experimental data. ${ }^{[85]}$ Here, for a $1.4 \mathrm{~mm}$-thick sheet, the adiabatic critical strain rate was approximately $10^{-2} \mathrm{~s}^{-1}$. As discussed previously, specimen heating is also influenced by the extent of the exothermic martensite transformation. ${ }^{[81]}$ Therefore, deformation processing factors that influence DIMT (such as strain rate and strain state), could influence the Taylor-Quinney coefficient and the flow behavior, thereby controlling the temperature rise under adiabatic conditions. In cold stamping operations, several factors could further influence heat flow and consequently control DIMT. First, the nature of the sheet-tool interface could influence the flow of heat away from the specimen; in cases where the dies are cold, heat flow out of the specimen could be enhanced significantly. However, repeated stampings often cause dies to heat to above room temperature, potentially mitigating this effect. Besides heat flow from the workpiece to the dies, frictional heating at the sheet-tool interface could also manipulate the temperature of the sheet.

Based on Figures 4, 5, and 8, trends in ductility, strain hardening and DIMT appear to saturate at the adiabatic critical strain rate $\left(10^{-2} \mathrm{~s}^{-1}\right.$, for monotonically loaded QP980). However, because no tensile tests were performed at strain rates greater than $10^{-1} \mathrm{~s}^{-1}$, it is unclear if these trends would further evolve for QP980 deformed at higher strain rates. The summary of literature reported below aims to resolve some potential shifts in strain hardening and DIMT for TRIP-assisted AHSS, including for rates greater than $10^{-1} \mathrm{~s}^{-1}$.

A summary of the strain rate dependence of DIMT and mechanical response for a variety of TRIP-assisted AHSS is provided in Tables I and II, respectively. For Q\&P, TRIP, Medium-Mn, and austenitic and duplex stainless steels, many authors reported that increasing strain rates from quasi-static $\left(\sim 10^{-4} \mathrm{~s}^{-1}\right)$ to intermediate $\left(\sim 10^{-1} \mathrm{~s}^{-1}\right)$ suppressed DIMT, partially due to adiabatic heating. For example, Enloe et al. and Savic et al. reported strain rate dependent work hardening, elongation, and strength in TRIP and Q\&P steels, respectively; in both studies, thermal stabilization of austenite and modified dislocation slip phenomena due to elevated strain rates exhibited potentially counteracting effects on the formation of martensite. ${ }^{[86,87]}$ Furthermore, in a

Table I. Strain Rate Dependence of DIMT in TRIP-Assisted AHSS ( $\star=$ This Study)

\begin{tabular}{|c|c|c|c|c|}
\hline Effect of Increasing Strain Rate on DIMT & Q\&P & TRIP & Medium-Mn & Stainless \\
\hline DIMT was suppressed by increasing strain rate & $\star, 77,85,96$ & 53,101 & $40,84,102$ & $30,31,54,103-105$ \\
\hline DIMT did not vary significantly & $40,88,89,106$ & 90,107 & - & - \\
\hline DIMT was accelerated at dynamic strain rates $\left(\sim 100 \mathrm{~s}^{-1}\right)$ & $85,95,96$ & 86 & - & - \\
\hline $\begin{array}{l}\text { Strain rate effects on DIMT were observed at low strains (prior to strong } \\
\text { deformation-induced heat accumulation) }\end{array}$ & 85,95 & 86 & - & $30,54,103,105$ \\
\hline
\end{tabular}

Table II. Strain Rate Dependence of the Tensile Response of TRIP-Assisted AHSS $(\star=$ This Study)

\begin{tabular}{|c|c|c|c|c|}
\hline Effect of Increasing Strain Rate on Mechanical Response & Q\&P & TRIP & Medium-Mn & Stainless \\
\hline Reduced work hardening rate at high strains & $\star, 87$ & 101,108 & $38,40,84$ & $54,79,109$ \\
\hline $\begin{array}{l}\text { Decrease in tensile elongation with increase in strain rate from } \\
\text { quasi-static }\left(\sim 10^{-4} \mathrm{~s}^{-1}\right) \text { to intermediate }\left(\sim 10^{-1} \mathrm{~s}^{-1}\right) \text {. No high rate } \\
\text { samples were tested }\end{array}$ & $\star, 98$ & - & - & 109 \\
\hline $\begin{array}{l}\text { As the strain rate was increased from quasi-static to intermediate, } \\
\text { tensile elongation decreased. As strain rate increased from } \\
\text { intermediate to dynamic }\left(\sim 100 \mathrm{~s}^{-1}\right) \text {, elongation increased, } \\
\text { forming a "ductility trough" }\end{array}$ & 40,96 & $90,101,107,110-112$ & $38,40,102$ & $54,103,113$ \\
\hline $\begin{array}{l}\text { Strain rate dependence was coupled with pre-deformation speci- } \\
\text { men temperature }\end{array}$ & 98 & 114 & 40,84 & 115 \\
\hline $\begin{array}{l}\text { Strain rate sensitivity was low at quasi-static to intermediate rates } \\
\text { but increased significantly at dynamic rates }\end{array}$ & $35,40,85,106$ & $107,111,112$ & - & - \\
\hline Necking behavior changed & 116 & - & 102 & - \\
\hline
\end{tabular}


study that incorporated synchrotron diffraction experiments and crystal plasticity modeling of isothermal and adiabatic conditions, Connolly et al. concluded that although temperature rise partially suppressed DIMT at intermediate strain rates $\left(8 \cdot 10^{-2} \mathrm{~s}^{-1}\right)$, the strain rate dependence of DIMT could not be attributed to temperature rise alone. ${ }^{[77]}$ In some studies of Q\&P and TRIP steels, DIMT did not vary significantly during deformation at quasi-static or dynamic rates. ${ }^{[40,88-90]}$ In general, for Q\&P steel microstructures, the mechanical stability of austenite is high and austenite volume fractions are relatively small, so perhaps a change in transformation behavior occurred, but was not easily resolvable; accurate measurement of austenite fractions in these steels remains challenging. ${ }^{[91,92]}$ Another potential source of variability between studies arises due to evaluation of different austenitic microstructures; for example, austenite morphology and grain size can greatly affect the extent of DIMT because of the differences in alloy content, proximity to lath martensite and intercritical ferrite, and dislocation density of the lath martensite. ${ }^{[93,94]}$ Although increasing strain rate from quasi-static to intermediate rates generally suppressed or did not drastically alter DIMT, a different behavior arose at strain rates above the adiabatic critical strain rate. For Q\&P steels, Zou et al. and Wang et al. described an acceleration in DIMT at strain rates above the adiabatic threshold, likely due to an increase in the number of martensite nucleation sites ${ }^{[85,95]}$; further characterization is warranted to identify what aspects of the microstructure controlled this promising behavior.

The TRIP-effect theory postulates that DIMT delays necking by locally increasing the strain hardening rate. ${ }^{[16,17]}$ If DIMT is suppressed at a given strain rate, then it is reasonable that the TRIP-effect will be less active. Therefore, the strain hardening rate will be decreased. This behavior was observed here for a $\mathrm{Q} \& \mathrm{P}$ steel deformed at quasi-static to intermediate rates. It is notable that a trough in ductility was reported at intermediate strain rates for multiple types of AHSS, including Q\&P steels ${ }^{[40,96]}$; the root cause is possibly related to a decreasing chemical driving force (due to adiabatic heating) and increasing mechanical driving force (due to larger stresses) for DIMT as strain rates increase. In addition to the TRIP-effect, some recent studies have shown that strain rate dependence of dislocation density in martensite and austenite affect strain hardening. For example, Hao et al. suggested that dislocation absorption by retained austenite (DARA ${ }^{[97]}$ ) is prominent at quasi-static rates and suppressed at dynamic rates. ${ }^{[70]}$ Meanwhile, Wang et al. reported that despite more complete DIMT at dynamic strain rates, lower dislocation density in martensite reduced the work hardening rate. ${ }^{[95]}$ Elucidating the root cause(s) of the trough in ductility should be of significant interest to the stamping community, because the trough is potentially problematic for predicting deformation behavior in stamping operations and vehicle crashes. Characterizing the ductility trough could allow stamping parameters to be tailored for specific material attributes, such as thickness and microstructure; for example, if a minimum ductility is reached at a strain rate of $10^{-1} \mathrm{~s}^{-1}$, then press displacement rates could be selected to exceed this minimum strain rate in critical regions (i.e., areas of high strain), thereby avoiding the ductility loss. Strain path and strain state dependence of the ductility trough should also be explored; for instance, it is currently unclear if the ductility troughs reported in literature for tension also exist in other strain states (e.g., plane strain and balanced biaxial tension), where necking criteria and DIMT are different.

Several studies have reported that the dependence of mechanical behavior on strain rate was contingent on the temperature of the specimen before deformation. For a Q\&P steel, Frint et al. suggested that strain rate sensitive ductility was more pronounced at $200{ }^{\circ} \mathrm{C}$ than at room temperature. ${ }^{[98]}$ In addition to dislocation slip, dislocation recovery, and DIMT, interface plasticity was proposed as a relevant mechanism at elevated temperatures. Recently, a greater understanding of interface plasticity in AHSS microstructures has been reached,${ }^{[99,100]}$ but has not yet been satisfactorily applied in formability studies.

\section{Recommendations for Future Research}

The results presented in this paper suggest that controlling austenite stability at various strain rates is critical for optimizing flow behavior in forming operations and the properties and performance of finished parts. Therefore, understanding how aspects of Q\&P microstructures control the TRIP-effect could greatly improve the viability of Q\&P steels. To reach a deeper understanding, the following are recommendations for areas of concentration in future research:

\section{Investigate the mechanism(s) that control the trough in ductility.}

Despite extensive reports of a trough in ductility at intermediate rates for many TRIP-assisted AHSS (see Figure 5(c), for example), a mechanism for this behavior has not been fully established. It is theorized that the ductility trough may be caused by a competition between a reduced chemical driving force, an increasing number of martensite nucleation sites, and an increasing mechanical driving force for DIMT. Deconvoluting the influences of strain rate and strain-induced heat accumulation deserves some attention; for a metastable austenitic stainless steel, Vázquez-Fernández et al. concluded that strain rate likely affects the extent of DIMT, perhaps by increasing the stress required for a partial dislocation to glide in a shear band. ${ }^{[105]}$ The rapid development of in-situ phase volume fraction analysis capabilities may also be useful to clarify the role of DIMT and microstructure damage accumulation on strain hardening and tensile elongation. ${ }^{[95]}$

\section{Expand test matrices to include more strain states, strain rates, and temperatures.}

Several recent studies evaluated forming performance of Q\&P steels by creating forming limit diagrams. ${ }^{[117,118]}$ Of particular interest, Liu et al. reported that the formability was reduced as the strain rate increased 
from $10^{-2}$ to $1 \mathrm{~s}^{-1}$ [119] Three additional studies attempted to link formability to the stability of retained austenite for industrially relevant stamping geometries. ${ }^{[33,36,120]}$ Chiriac et al. stamped B-pillar components using third generation TRIP-assisted AHSS with similar chemical composition and UTS, but different phase volume fractions, austenite stabilities, and strain hardening behaviors; austenite stability appeared to control surface strain distribution at low to medium strains and strain localization at high strains. ${ }^{[33]}$ Despite these noteworthy contributions, additional testing is needed to elucidate the connection between DIMT and formability for a greater number of strain states, strain rates, and temperatures. Path sensitive deformation characteristics, such as the Bauschinger effect, should also be explored.

\section{Incorporate the strain rate dependence of DIMT into} formability and crash models.

The strain rate dependent DIMT and ductility of TRIP-assisted AHSS is not easily compatible with existing constitutive models for deformation at dynamic rates. ${ }^{[121]}$ Because the TRIP-effect profoundly influences flow behavior in these steels, developing reasonable empirical models for DIMT that incorporate strain state, strain rate, and temperature rise during non-isothermal deformation will be crucial for informing microstructure design. ${ }^{[40,122-124]}$ Currently, modeling the role of the TRIP-effect on plasticity and fracture is of significant interest for optimizing microstructure design and predicting forming limits and crash performance. ${ }^{[122-124]}$ However, these models have not yet incorporated the strain rate sensitivity of DIMT.

\section{CONCLUSIONS}

For a quenched and partitioned third generation advanced high strength steel (QP980), these experiments demonstrated the necessity of concurrent strain, surface temperature, and retained austenite volume fraction measurements during formability testing. Based on characterization of the tensile stress-strain behavior, deformation-induced heating, and progression of the martensite transformation for QP980, the following conclusions can be made:

1. Progressive transformation of retained austenite to martensite was observed during tensile deformation of QP980 at every strain rate tested $\left(10^{-4}\right.$ to $10^{-1}$ $\left.\mathrm{s}^{-1}\right)$. DIMT was most pronounced at the slowest strain rate tested $\left(10^{-4} \mathrm{~s}^{-1}\right)$, likely due to a lack of deformation-induced heat accumulation.

2. At the two higher strain rates $\left(10^{-2}\right.$ and $\left.10^{-1} \mathrm{~s}^{-1}\right)$, the instantaneous strain hardening rate decreased dramatically near the UTS, resulting in a relative 30 pet reduction in uniform elongation and toughness. Based upon modified C-J analysis and surface temperature measurements, this was attributed to the suppression of DIMT by quasi-adiabatic heating. No evidence of a change in macroscopic or microscopic fracture behavior was observed.

3. The mechanical response and DIMT behavior for the QP980 was reported and compared to other TRIP-assisted AHSS results in the literature. Suppression of the TRIP-effect by deformation-induced heating is well documented as strain rates are increased from low $\left(10^{-4} \mathrm{~s}^{-1}\right)$ to intermediate $\left(10^{-1} \mathrm{~s}^{-1}\right)$, although mechanistic explanations are still unclear. At high strain rates (greater than $\sim 10 \mathrm{~s}^{-1}$ ), the TRIP-effect is increasingly active, despite quasi-adiabatic heating conditions, perhaps due to an increase in the number of martensite nucleation sites. Correspondingly, a trough in ductility at intermediate strain rates is reported for a broad variety of AHSS.

\section{ACKNOWLEDGMENTS}

The authors would like to thank Prof. Matthias Militzer for his thoughtful suggestions during the peer review process. The financial support of the Advanced Steel Processing and Products Research Center (ASPPRC), an industry-university cooperative research center at the Colorado School of Mines, Golden, CO is gratefully acknowledged. Christopher Finfrock, Melissa Thrun, and Kester Clarke acknowledge support from the National Science Foundation division of Civil, Mechanical and Manufacturing Innovation (NSF-CMMI) through award no. 1752530.

\section{AUTHOR CONTRIBUTIONS}

$C F$ : conceptualization, formal analysis, investigation, writing - original draft, visualization. $M T$ : investigation, writing - review and editing. $D B$ : writing review and editing, visualization. $T B$ : investigation. $A C$ : conceptualization, writing - review and editing, supervision. $K C$ : conceptualization, writing - review and editing, supervision.

\section{DATA AVAILABILITY}

The raw and processed data required to reproduce these findings are available to download from Mendeley Data at the following URL: https://data.mendeley. com/datasets/fbvwzggmwv/draft?a = 585ec634-5cc6-433 3-8042-f487f75bbc 25 .

\section{CONFLICT OF INTEREST}

The authors declare no conflicts of interest. 


\section{REFERENCES}

1. H. Helms and U. Lambrecht: Int. J. Life Cycle Assessm., 2007, vol. 12 , pp. $58-64$.

2. D. Raabe, C.C. Tasan, and E.A. Olivetti: Nature, 2019, vol. 575, pp. 64-74.

3. A.D. Brooker, J. Ward, and L. Wang: SAE Technical Papers, Technical Report No. 2013-01-0381, https://doi.org/10.4271/201301-0381.

4. H.C. Kim and T.J. Wallington: Environ. Sci. Technol., 2013, vol. 47, pp. 14358-66.

5. O. Bouaziz, H. Zurob, and M. Huang: Steel Res. Int., 2013, vol. 84, pp. 937-47.

6. D.K. Matlock and J.G. Speer: in Microstructure and Texture in Steels, A. Haldar, S. Suwas, and D. Bhattacharjee, eds., Springer, London, 2009, pp. 185-205.

7. P. Russo Spena, M. De Maddis, G. D'Antonio, and F. Lombardi: Metals, 2016, https://doi.org/10.3390/met6110270.

8. P. Russo Spena, L. Cortese, M. De Maddis, and F. Lombardi: Steel Res. Int., 2016, vol. 87, pp. 1592-1600.

9. K.M. Molnar: Colorado School of Mines, 2020

10. D. Bhattacharya: Mater. Sci. Technol., 2018, vol. 34, pp. 1809-29.

11. J. Speer, D.K. Matlock, B.C. De Cooman, and J.G. Schroth: Acta Mater., 2003, vol. 51, pp. 2611-22.

12. A.M. Streicher, J.G. Speer, D.K. Matlock, and B.C. De Cooman in International Conference on Advanced High-Strength Sheet Steels for Automotive Applications, Winter Park, Colorado, 2004, pp. $51-62$.

13. D.V. Edmonds, K. He, F.C. Rizzo, B.C. De Cooman, D.K. Matlock, and J.G. Speer: Mater. Sci. Eng. A, 2006, vols. 438-440, pp. 25-34

14. A.J. Clarke, J.G. Speer, M.K. Miller, R.E. Hackenberg, D.V. Edmonds, D.K. Matlock, F.C. Rizzo, K.D. Clarke, and E. De Moor: Acta Mater., 2008, vol. 56, pp. 16-22.

15. L. Wang and J.G. Speer: Metall. Microstruct. Anal., 2013, vol. 2, pp. 268-81.

16. F.D. Fischer, G. Reisner, E. Werner, K. Tanaka, G. Cailletaud, and T. Antretter: Int. J. Plast., 2000, vol. 16, pp. 723-48.

17. W. Bleck, X. Guo, and Y. Ma: Steel Res. Int., 2017, vol. 88 , https://doi.org/10.1002/srin.201700218.

18. G.W. Greenwood and R.H. Johnson: Proc. R. Soc. A, 1965 , vol. 283, pp. 403-22.

19. C.L. Magee: Carnegie Institute of Technologie University Ph.D Thesis, 1966.

20. E. De Moor, S. Lacroix, A.J. Clarke, J. Penning, and J.G. Speer: Metall. Mater. Trans. A, 2008, vol. 39A, pp. 2586-95.

21. E. De Moor, J.G. Speer, D.K. Matlock, and D.N. Hanlon: in Contributed Papers from Materials Science \& Technology (MS\&T11), 2011, pp. 568-79.

22. C.B. Finfrock, A.J. Clarke, G.A. Thomas, and K.D. Clarke: Metall. Mater. Trans. A, 2020, vol. 51A, pp. 2025-34.

23. P.J. Gibbs, E. De Moor, M.J. Merwin, B. Clausen, J.G. Speer, and D.K. Matlock: Metall. Mater. Trans. A, 2011, vol. 42, pp. 3691-3702.

24. J.G. Speer, E. De Moor, K.O. Findley, D.K. Matlock, B.C. De Cooman, and D.V. Edmonds: Metall. Mater. Trans. A, 2011, vol. $42 \mathrm{~A}$, pp. $3591-3601$

25. J. Hidalgo, K.O. Findley, and M.J. Santofimia: Mater. Sci. Eng. $A$, 2017, vol. 690 , pp. 337-47.

26. K.O. Findley, J. Hidalgo, R.M. Huizenga, and M.J. Santofimia: Mater. Des., 2017, vol. 117, pp. 248-56.

27. J. Kähkönen, D.T. Pierce, J.G. Speer, E. de Moor, G.A. Thomas, D. Coughlin, K. Clarke, and A. Clarke: JOM, 2015, vol. 68, pp. $210-14$.

28. G.A. Thomas, J.G. Speer, and D.K. Matlock: Metall. Mater. Trans. A, 2011, vol. 42A, pp. 3652-59.

29. E. Emadoddin, H. Asmari, and A.H. Zadeh: Int.J. Mater. Form. 2009, vol. 2, pp. 781-84.

30. S.S. Hecker, M.G. Stout, K.P. Staudhammer, and J.L. Smith: Metall. Trans. A, 1982, vol. 13, pp. 619-26.

31. L.E. Murr, K.P. Staudhammer, and S.S. Hecker: Metall. Trans. A, 1982, vol. 13 , pp. $627-35$.

32. A.M. Streicher: Colorado School of Mines M.S. Thesis, 2002.
33. C. Chiriac, R. Sohmshetty, J. Balzer, T. Mueller, and J.D. Ju: IOP Conf. Ser., 2004, https://doi.org/10.1088/1757-899x/418/1/ 012004 .

34. J.Y. Lee, L. Xu, F. Barlat, R.H. Wagoner, and M.G. Lee: Exp. Mech., 2013, vol. 53, pp. 1681-92.

35. J. He, G. Han, S. Li, and D. Zou: Int. J. Mech. Sci., 2019, vol. 152, pp. 198-210.

36. W. Wu, Y.W. Wang, P. Makrygiannis, F. Zhu, G.A. Thomas, L.G. Hector, X. Hu, X. Sun, and Y. Ren: Mater. Sci. Eng. A, 2018, vol. 711, pp. 611-23.

37. A.K. Ghosh: J. Eng. Mater. Technol., 1977, vol. 99, pp. 264-74.

38. R. Alturk, L.G. Hector, C. Matthew Enloe, F. Abu-Farha, and T.W. Brown: JOM., 2018, vol. 70, pp. 894-905.

39. X. Yang, L.G. Hector, and J. Wang: Exp. Mech., 2014, vol. 54, pp. 775-89.

40. W. Poling: Colorado School of Mines Ph.D Thesis, 2017.

41. J.T. Benzing, W.A. Poling, D.T. Pierce, J. Bentley, K.O. Findley, D. Raabe, and J.E. Wittig: Mater. Sci. Eng. A, 2018, vol. 711, pp. 78-92.

42. C. Finfrock, C.G. Becker, T. Ballard, G. Thomas, K. Clarke, and A. Clarke: in Contributed Papers from Materials Science \& Technology (MS\&T19), Portland, Oregon, 2019, pp. 1236-43. https://doi.org/10.7449/2019/mst_2019_1236_1243.

43. K.D. Clarke: Colorado School of Mines M.S. Thesis, 2002

44. K.D. Clarke, R.J. Comstock, M.C. Mataya, D.K. Matlock, J.G. Speer, and G.P. Martins: SAE Technical Papers, Technical Report No. 2003-01-0526, https://doi.org/10.4271/2003-01-0526.

45. D.A. Porter and K.E. Easterling: Phase Transformations in Metals and Alloys, 2nd ed., Springer, New York, 1992.

46. G.F. Bolling and R.H. Richman: Scr. Metall., 1970, vol. 4, pp. $539-44$

47. G.B. Olson and C. Morris: J. Less-Common Met., 1972, vol. 28, pp. $107-18$

48. Z. Wang and M.X. Huang: Metall. Mater. Trans. A, 2019, vol. 50 , pp. $5650-55$.

49. K. Sugimoto, M. Kobayashi, and S. Hashimoto: Metall. Mater. Trans. A, 1992, vol. 23A, pp. 3085-91.

50. B.C. De Cooman: Curr. Opin. Solid State Mater. Sci., 2004, vol. 8, pp. 285-303.

51. W. Feng, Z. Wu, L. Wang, and J.G. Speer: Steel Res. Int., 2013, vol. 84, pp. 246-52.

52. G.B. Olson and M. Cohen: Metall. Trans. A, 1975, vol. 6A, pp. 791-95

53. W.J. Dan, W.G. Zhang, S.H. Li, and Z.Q. Lin: Comput. Mater. Sci., 2007, vol. 40, pp. 101-07.

54. J. Talonen, P. Nenonen, G. Pape, and H. Hänninen: Metall. Mater. Trans. A, 2005, vol. 36A, pp. 421-32.

55. M. Bhargava, S. Chakrabarty, V. Kumar, A. Tewari, and S.K. Mishra: 2018, vol. 152, pp. 65-77.

56. ASTM International E8/E8M-16a, https://doi.org/10.1520/e0008 $\mathrm{e} 0008 \mathrm{~m}-16 \mathrm{a}$

57. G.E. Dieter: Mechanical Metallurgy, 3rd ed., McGraw-Hill, New York, 1961

58. B.K. Jha, R. Avtar, V.S. Dwivedi, and V. Ramaswamy: J. Mater. Sci. Lett., 1987, vol. 6, pp. 891-93.

59. ASTM International E975-13, https://doi.org/10.1520/e0975-13.

60. B.D. Cullity: Elements of X-ray Diffraction, 1 st ed., Addison-Wesley Publishing Company Inc, Reading, MA, 1956.

61. W. Li, H. Gao, H. Nakashima, S. Hata, and W. Tian: Mater. Charact., 2016, vol. 118, pp. 431-37.

62. P. Haasen and A. Kelly: Acta Metall., 1957, vol. 5, pp. 192-99.

63. L.M. Brown: Philos. Mag., 2010, vol. 90, pp. 4147-52

64. D. Hull and D.J. Bacon: Introduction to Dislocations, 5th ed., Elsevier, Burlington, MA, 2011.

65. D.M. Field and D.C. Van Aken: Metall. Mater. Trans. A, 2018, vol. 49A, pp. 1152-66.

66. T. Waterschoot, A.K. De, S. Vandeputte, and B.C. De Cooman: Metall. Mater. Trans. A, 2003, vol. 34A, pp. 781-91.

67. R.W. Rathbun, D.K. Matlock, and J.G. Speer: Scripta Mater., 2000, vol. 42, pp. 887-91.

68. M. Thrun, C. Finfrock, A. Clarke, and K. Clarke: Front. Mater. Struct. Mater., 2021, vol. 7, art. no. 615361

69. J. Min, L.G. Hector, L. Zhang, L. Sun, J.E. Carsley, and J. Lin: Mater. Des., 2016, vol. 95, pp. 370-86. 
70. Q. Hao, S. Qin, Y. Liu, X. Zuo, N. Chen, W. Huang, and Y. Rong: Mater. Sci. Eng. A, 2016, vol. 662, pp. 16-25.

71. F. Abu-Farha, X. Hu, X. Sun, Y. Ren, L.G. Hector, G. Thomas, and T.W. Brown: Metall. Mater. Trans. A, 2018, vol. 49A, pp. 2583-96.

72. X.H. Hu, X. Sun, L.G. Hector, and Y. Ren: Acta Mater., 2017, vol. 132 , pp. $230-44$.

73. A.K. Ghosh: Acta Metall., 1977, vol. 25, pp. 1413-24.

74. G.C. Soares, B.M. Gonzalez, and L. de Arruda Santos: Mater. Sci. Eng. A, 2017, vol. 684, pp. 577-85.

75. A. Skowronek and A. Grajcar: Materials, 2020, vol. 13, pp. 25-40.

76. D. Salehiyan, J. Samei, B.S. Amirkhiz, L.G. Hector, and D.S. Wilkinson: Metall. Mater. Trans. A, 2020, vol. 51A, pp. 4524-39.

77. D.S. Connolly, C.P. Kohar, W. Muhammad, L.G. Hector, R.K. Mishra, and K. Inal: Int. J. Plast., 2020, https://doi.org/ 10.1016/j.ijplas.2020.102757.

78. G.I. Taylor and H. Quinney: Proc. R. Soc. Lond. Ser. A, 1934, vol. 143, pp. 307-26.

79. A. Andrade-Campos, F. Teixeira-Dias, U. Krupp, F. Barlat, E.F. Rauch, and J.J. Grácio: Strain, 2010, vol. 46, pp. 283-97.

80. W.D. Callister and D.G. Rethwisch: Materials Science and Engineering: An Introduction, 10th ed., Wiley Global Education, New York, 2018.

81. N.I. Vazquez-Fernandez, G.C. Soares, J.L. Smith, J.D. Seidt, M. Isakov, A. Gilat, V.T. Kuokkala, and M. Hokka: J. Dyn. Behav. Mater., 2019, vol. 5, pp. 221-29.

82. H. Kim, J. Lee, F. Barlat, D. Kim, and M.G. Lee: Acta Mater., 2015, vol. 97, pp. 435-44.

83. J. Coryell, V. Savic, L. Hector, and S. Mishra: SAE Technical Papers Technical Report No. 2013-01-0610, https://doi.org/10.42 71/2013-01-0610.

84. R. Rana, E. De Moor, J.G. Speer, and D.K. Matlock: JOM, 2018, vol. 70, pp. 706-13.

85. D.Q. Zou, S.H. Li, and J. He: Mater. Sci. Eng. A, 2017, vol. 680, pp. 54-63.

86. C. Enloe, V. Savic, W. Poling, L. Hector, and R. Alturk: SAE Technical Papers, Technical Report No. 2019-01-0521, 2019, pp. $1-10$.

87. V. Savic, L. Hector, R. Alturk, and C. Enloe: SAE Technical Papers, Technical Report No. 2020-01-0754, 2020, pp. 1-8.

88. X. Yang, X. Xiong, Z. Yin, H. Wang, J. Wang, and D. Chen: Exp. Mech., 2014, vol. 54, pp. 641-52.

89. H. Wang, W. Zhang, D. Ma, B. Ma, D. Chen, X. Yang, and C. Fan: Acta Mech. Solida Sin., 2017, vol. 30, pp. 484-92.

90. Y. Gao, C. Xu, Z.P. He, Y.L. He, and L. Li: J. Iron Steel Res. Int., 2015, vol. 22, pp. 48-54.

91. P.J. Jacques, S. Allain, O. Bouaziz, A. De, A.-F. Gourgues, B.M. Hance, Y. Houbaert, J. Huang, A. Iza-Mendia, S.E. Kruger, M. Radu, L. Samek, J. Speer, L. Zhao, and S. van der Zwaag: Mater. Sci. Technol., 2009, vol. 25, pp. 567-74.

92. T. Gnäupel-Herold and A. Creuziger: Mater. Sci. Eng. A, 2011, vol. 528, pp. 3594-3600.

93. X.C. Xiong, B. Chen, M.X. Huang, J.F. Wang, and L. Wang: Scripta Mater., 2013, vol. 68, pp. 321-24.

94. D. De Knijf, C. Föjer, L.A.I. Kestens, and R. Petrov: Mater. Sci. Eng. A, 2015, vol. 638, pp. 219-27.

95. M. Wang and M.X. Huang: Acta Mater., 2020, vol. 188, pp. 551-59.

96. C. Liu, L. Wang, and Y. Liu: Mater. Sci. Forum, 2013, vol. 749, pp. 401-06.

97. K. Zhang, M. Zhang, Z. Guo, N. Chen, and Y. Rong: Mater. Sci. Eng. A, 2011, vol. 528, pp. 8486-91.
98. P. Frint, T. Kaiser, T. Mehner, E. Bruder, M. Scholze, B. Mašek, T. Lampke, and M.F.-X. Wagner: Sci. Rep., 2019, vol. 9, pp. 1-7.

99. F. Maresca and W.A. Curtin: Acta Mater., 2017, vol. 134, pp. 302-23.

100. C. Du, R. Petrov, M.G.D. Geers, and J.P.M. Hoefnagels: Mater. Des., 2019, 172, vol. 172.

101. Z. Gronostajski, A. Niechajowicz, R. Kuziak, J. Krawczyk, and S. Polak: J. Mater. Process. Technol., 2017, vol. 242, pp. 246-59.

102. S. Sevsek, C. Haase, and W. Bleck: Metals, 2019, vol. 9, pp. 1-20.

103. J.A. Lichtenfeld, M.C. Mataya, and C.J. Van Tyne: Metall. Mater. Trans. A, 2006, vol. 37A, pp. 147-61.

104. A. Das, S. Tarafder, and P.C. Chakraborti: Mater. Sci. Eng. A, 2011, vol. 529, pp. 9-20.

105. N.I. Vázquez-Fernández, T. Nyyssönen, M. Isakov, M. Hokka, and V.T. Kuokkala: Acta Mater., 2019, vol. 176, pp. 134- 44.

106. P. Xia, F. Vercruysse, R. Petrov, I. Sabirov, M. Castillo-Rodríguez, and P. Verleysen: Mater. Sci. Eng. A, 2019, vol. 745, pp. 53-62.

107. I. Choi, D. Son, S.J. Kim, D.K. Matlock, and J.G. Speer: $S A E$ Technical Papers, Technical Report No. 2006-01-1434, https://doi. org/10.4271/2006-01-1434.

108. J.H. Kim, D. Kim, N.H. Han, F. Barlat, and L. Myoung-Gyu: Mater. Sci. Eng. A, 2013, vol. 559, pp. 222-31.

109. J.Y. Choi, J. Lee, K. Lee, J.-Y. Koh, J.-H. Cho, H.N. Han, and K.-T. Park: Mater. Sci. Eng. A, 2016, vol. 666, pp. 280-87.

110. Z. He, Y. He, Y. Ling, Q. Wu, Y. Gao, and L. Li: J. Mater. Process. Technol., 2012, vol. 212, pp. 2141-47.

111. I.D. Choi, D.M. Kim, S.J. Kim, D.M. Bruce, D.K. Matlock, and J.G. Speer: Met. Mater. Int., 2006, vol. 12, pp. 13-19.

112. I. Choi, Y. Park, D. Son, S.J. Kim, and M. Moon: Met. Mater. Int., 2010, vol. 16, pp. 27-33.

113. S.V. Prasad and K.N. Jonnalagadda: in Dynamic Behavior of Materials, Volume 1: Proceedings of the 2012 Annual Conference on Experimental and Applied Mechanics, V. Chalivendra, B. Song, and D. Casem, eds., Springer Science \& Business Media, 2012, pp. 101-08.

114. S. Curtze, V.T. Kuokkala, M. Hokka, and P. Peura: Mater. Sci. Eng. A, 2009, vol. 507, pp. 124-31.

115. G.L. Huang, D.K. Matlock, and G. Krauss: Metall. Trans. A, 1989, vol. 20A, pp. 1239-46.

116. L. Ding, J. Lin, J. Min, Z. Pang, and Y. Ye: Chin. J. Mech. Eng., 2013, vol. 26, pp. 448-53.

117. X. Chen, C. Niu, C. Lian, and J. Lin: Proc. Eng., 2017, vol. 207, pp. 556-61.

118. M. Bhargava, A. Tewari, and S.K. Mishra: Mater. Des., 2015, vol. 85 , pp. $149-55$.

119. R. Liu, L. Sun, X. Wang, L. Lin, L. Zhang, and J. Lin: SAE Int. J. Mater. Manuf., 2014, vol. 7, pp. 583-87.

120. Y. Wang: in Great Designs in STEEL Seminar, 2016.

121. G.R. Johnson and W.H. Cook: in Seventh International Symposium on Ballistics, 1983, pp. 541-47.

122. F.X.C. Andrade, M. Feucht, A. Haufe, and F. Neukamm: Int. J. Fract., 2016, vol. 200, pp. 127-50.

123. Z. Li, R. Kiran, J. Hu, L.G. Hector, and A.F. Bower: Int. J. Fract., 2020, vol. 221, pp. 53-85.

124. T. Park, L.G. Hector, X. Hu, F. Abu-Farha, M.R. Fellinger, H. Kim, R. Esmaeilpour, and F. Pourboghrat: Int. J. Plast, 2019, vol. 120 , pp. 1-46.

Publisher's Note Springer Nature remains neutral with regard to jurisdictional claims in published maps and institutional affiliations. 